\title{
Stability of Soil Block on Low Interface Friction Plane with and without Side Supports
}

\author{
Rithy Ouch ${ }^{1}$, Boonchai Ukritchon ${ }^{1, *}$, and Thirapong Pipatpongsa ${ }^{2}$ \\ 1 Geotechnical Research Unit, Department of Civil Engineering, Faculty of Engineering, Chulalongkorn \\ University, Bangkok 10330, Thailand \\ 2 Department of Urban Management, Kyoto University, Katsura Campus Nishikyo-ku, Kyoto, 615-8540, \\ Japan \\ *E-mail: boonchai.uk@gmail.com
}

\begin{abstract}
Slope instability is a challenging problem in geotechnical engineering. The main focus of this paper is to investigate the stability of a soil block, with and without side supports, resting on a low interface friction plane by employing a three-dimensional finite element analysis (3D FEA). In the numerical model, the soil block is modeled as a volume element with Mohr-Coulomb material in a drained condition. Interface elements are used at the bottom plane in order to capture the shear sliding on the interface plane. Side interface elements with fully rough surfaces are also used in the slip analysis with side supports. A failure analysis is performed by means of the gravity loading method. The results of 3D FEA are compared with those of the existing physical models for both cases. Extensive parametric studies of a slip analysis with side supports are carried out in order to develop an empirical equation for the stability number as a function of four normalized parameters. Finally, the paper presents an application of the proposed equation to the prediction of the failure width and the required width for the excavation of an actual mine.
\end{abstract}

Keywords: Three-dimensional finite element analysis, physical model, limit equilibrium method, slip analysis and empirical equation.

ENGINEERING JOURNAL Volume 20 Issue 2

Received 23 April 2015

Accepted 14 September 2015

Published 18 May 2016

Online at http://www.engj.org/

DOI:10.4186/ej.2016.20.2.123 


\section{Introduction}

Assessing slope stability is an important task in geotechnical engineering. In general, the instability of slopes may be induced by many factors, such as heavy rain, a complicated landform, hydrological and geological processes, earthquakes and cut slopes, etc. These factors have caused different modes of failure, such as circular slip, toppling, plane sliding and wedge sliding [1,2]. This paper presents the results of an investigation into the stability of a soil block, with and without side supports, resting on a low interface friction plane, as shown in Fig. 1. When the sides of the soil block are not supported, failure occurs due to the shear sliding of the soil block on the bottom plane with low interface friction. However, when the sides of the soil block are supported, failure occurs because of both the shear sliding of the soil block on the bottom plane with low interface friction and the shear sliding on both end supports. The latter case is important in practice since there is a similitude of the model with actual sites, such an open pit mine [3], as shown in Fig. 2. This Mae Moh mine in "Area 4.1" consists of two types of rock masses (shale and lignite); they rest on a bedding plane of clay seams that has low interface strength. When the lignite or shale at the toe part of the slope is excavated or removed, the rock mass on the slope may slide down along the clay seams. Thus, this actual behavior is similar to that of the studied model. The stability of this slope problem can be investigated by the limit equilibrium method (LEM), the method of limit analysis or the finite element analysis (FEA).

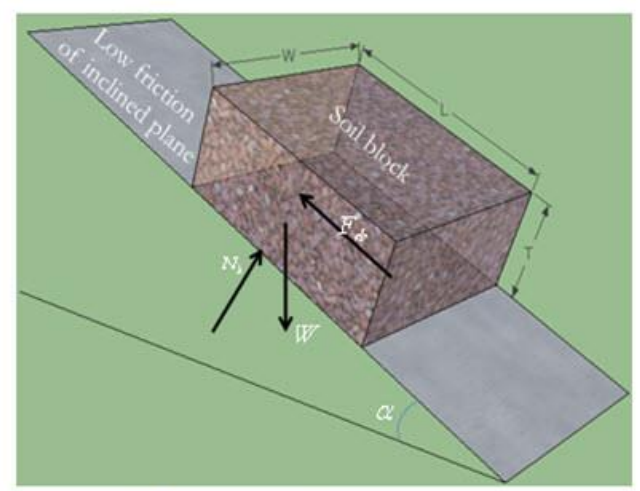

a) Slip analysis without side supports

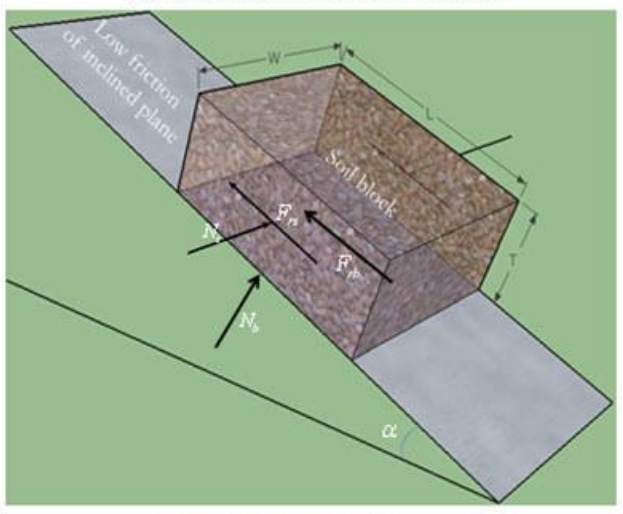

b) Slip analysis with side supports

Fig. 1. Problem definition of soil block resting on plane of low interface friction without and with side supports. 


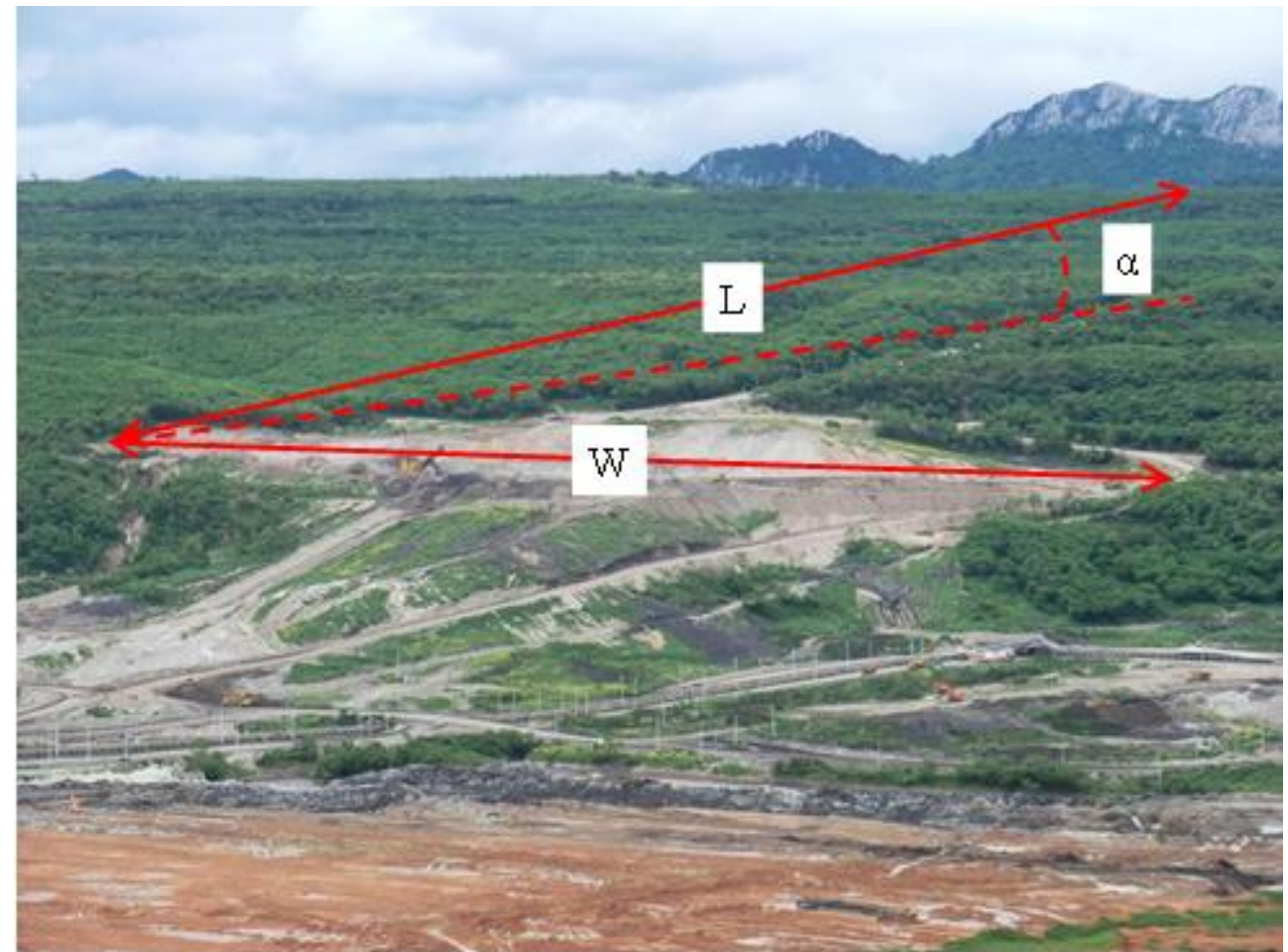

Fig. 2. Similitude of the studied model with an actual site (Area 4.1 of Mae Moh mine as of July 2011) [3].

Past researches [4-8] employed the limit equilibrium method (LEM) to analyze the stability of soil slopes and compared their results with those of other methods. The results of LEM were found to be similar to those of other methods if the derived LEM satisfied all conditions of global equilibrium. The problem of a soil block on a low interface friction plane without side supports can be solved by the equilibrium of force along the slope [9], as shown in Fig. 1. However, the problem of a soil block on a low interface friction plane with side supports cannot be solved, because the number of unknown forces existing on the block is greater than that of the equilibrium equations plus the Mohr-Coulomb yield criterion. To overcome this problem, [9] added another assumption such that the cohesive arch action for a slip analysis with side supports would follow a concept similar to that proposed by [10], who determined the width of the hopper in order to destabilize the material flows. The LEM equations for both problems will be presented later.

On the other hand, several authors $[8,11-13]$ have successfully employed the method of limit analysis $[4,14]$ to determine the stability of soil slopes. The results of a limit analysis can provide the rigorous lower bound and upper bound of the true collapse load. The lower bound theorem is essentially based on the statically admissible stress field, which satisfies the equilibrium, the stress boundary condition and the yield criterion. The results of the lower bound analysis are always lower than the exact collapse load. However, the upper bound theorem is based on the kinematically admissible velocity field, which satisfies the compatibility equation, the velocity boundary condition and the associated flow rule. The results of the upper bound analysis are always higher than the true collapse load. Although many authors have succeeded in applying the limit analysis to actual problems of slope stability or problems in the research field, most applications of the limit analysis have been restricted to two-dimensional problems. Few applications have been made to three-dimensional problems. Due to the 3D geometry of soil blocks with side supports, it is difficult to determine the statically admissible stress field of this problem using the lower bound analysis or the kinematically admissible velocity field using the upper bound analysis. Thus, there is no existing solution in the literature for this problem using the limit analysis.

The finite element analysis (FEA) has become popular in the field of engineering; it provides great advantages and capabilities for simulating the behaviors of physical problems with computational tools, but without the need to simplify the problems. Currently, newly proposed analytical methods in the field of engineering can be verified using FEA as a benchmark. Many researches in the past succeeded in applying the finite element method to investigate slope stability [15-19]. In general, FEA can simulate twodimensional (2D) and three-dimensional (3D) slope problems. Since the stability problem of soil blocks on 
a low interface friction plane with side supports is three-dimensional, the results of the 3D finite element method provide more realistic behavior for this particular problem. So far, solutions obtained with 3D FEA for this type of problem are not available in the literature.

Recently, the stability of soil blocks, with and without side supports, has been studied using the $1 \mathrm{~g}$ physical model [20-22]. The results of these studies have not only provided a significant understanding of the failure mechanism and the load transfer, based on the arch action, but they have also postulated an equation based on the limit equilibrium of force and stress along the arch. However, the performance of the finite element method in investigating the stability of soil blocks, with and without side supports, on a low interface friction plane has not been verified in previous studies. In this paper, therefore, 3D FEA is applied to investigate the stability of a soil block, with and without side supports, on a low interface friction plane. The results of this research are compared with those of existing physical models. An empirical equation, based on extensive parametric studies of data on 3D FEA, is proposed and applied to predict the failure width and the required width for an excavation at the actual site of a mining project.

\section{Numerical Approach}

Figure 1 shows the problem statement of a slip analysis with and without side supports. For both cases, a soil block with length $L$, width $W$ and thickness $T$ rests on an inclined plane of slope angle $\alpha$ with relatively low interface friction. Details of the parameters are summarized in Tables 1 and 2. The soil block has apparent cohesion $\mathrm{c}$ and friction angle $\phi$, while the interface strengths between the soil and the bottom plane are apparent interface adhesion $c_{i}$ and interface friction angle $\phi_{i}$. For the case of a slip analysis with side supports, the soil block is also supported by fully rough ends at both sides. The failure occurs due to the gravity force of the soil self-weight, which causes sliding at the bottom plane for both models. In addition, sliding may happen at both end supports for the case of the slip analysis with side supports.

In this paper, Plaxis 3D version 2013 [23], a three-dimensional finite element analysis program, is employed to analyze the stability problems of a soil block resting on an inclined plane. Figure 3 shows the 3D finite element models that correspond to the physical models for the slip tests, with and without side supports, conducted by [9]. Three series of the finite element analysis for a slip analysis without side supports are conducted to study: 1) the effect of soil width, 2) the effect of soil length and 3) the effect of soil thickness. In addition, two series of the finite element analysis for a slip analysis with side supports are also analyzed. Firstly, the models are used to study the effect of soil width, while the thickness and the length of the slope are kept constant. Secondly, the models are used to study the effect of soil length, while the thickness, width and slope angle are kept constant. The material in both physical tests (after [9]) includes silica sand and a Teflon sheet over a stiff aluminum plate used as the bottom support. Sand paper is attached to acrylic plates and the plates are used as the side supports only for the case of the slip tests with side supports. The geometry and the material properties inputted into the numerical models are the same as those used in the physical models. In the numerical models, three types of materials are used in the simulation, namely, soil volume, plate and interface elements. The plate, the interface and the soil volume elements represent the stiff aluminum plate, the Teflon sheet and the silica sand of the physical models, respectively.

Half and full models were used for the slip analyses with and without side supports, respectively. For both cases, plate and interface elements are added to the bottom plane. For the slip analysis with side supports, those elements are also added at one end of the side plane. The soil volumes of both analyses are modeled as Mohr-Coulomb material with the associated flow rule. For both cases, the behaviors of the interface element at the bottom plane are defined by the Mohr-Coulomb material with interface apparent adhesion and interface friction, which differ from those of soil volume. For the slip analysis with side supports, the side interface elements are set as fully rough surfaces of adjacent soil volume material corresponding to the expected behavior of the physical models as fully rough surfaces because sand paper was added to both side supports. The boundaries of the bottom plate of both models were fixed in all directions. For the slip analysis with side supports, the fixed boundary of the plate at the side plane was defined, while the symmetrical plane of the model was fixed only in the $x$-axis $\left(u_{x}=0\right)$ and movements in other directions were free $\left(u_{y}=u_{y}=\right.$ free). Figure 3 also illustrates details of the boundary conditions of both models. The typical finite element fine meshes of the models are shown in Fig. 4. 10-node tetrahedral elements are used for the soil volume elements, while 6-node elements are used for the plate elements. 12- 
node interface elements, placed between the plate and the soil elements, are used to simulate the soilstructure interaction behavior.

The material properties used in the finite element analysis follow those reported by [9]. Internal friction angle $\phi$ and apparent cohesion c of the humid silica sand, determined from direct shear tests, are $41.5^{\circ}$ and $0.358 \mathrm{kN} / \mathrm{m}^{2}$, respectively. Similarly, interface friction angle $\phi_{i}$ and interface adhesion $\mathrm{c}_{\mathrm{i}}$, between the humid silica sand and the Teflon sheet, were obtained from direct shear tests by putting the humid silica sand on top of the Teflon sheet. Their values are $18.5^{\circ}$ and $0.1 \mathrm{kN} / \mathrm{m}^{2}$, respectively. Details of those tests can be found in [9]. Poisson's ratio is 0.3 following typical drained material. The dilatancy angle is the same as the internal friction angle because of the associated flow rule. The plate elements are modeled as linear elastic models, where their Young's modulus is set at a high value in order to simulate stiff behavior. The material properties are summarized in Table 3. Note that though the controlled unit weight of soil block was 13.68 $\mathrm{kN} / \mathrm{m}^{3}$ in the experiments, the input unit weight for the finite element analysis is specified generally to 25 $\mathrm{kN} / \mathrm{m}^{3}$ as the initial value for calculating the failure unit weight.

According to the plastic bounding theorems developed by Drucker et al. [4, 14], there exists an exact limit load solution if the material follows the assumption of a perfectly plastic material and an associated flow rule. The associated flow rule specifies a constant rate of dilation during shearing such that a dilatation angle of soil is equal to a friction angle. The paper assumes the concept of an associated flow rule in the finite element analysis in order to obtain an approximate solution of a material whose a true limit load exists.

Based on a result of direct shear tests [21] on humid silica sand No. 6, the dilation angle varies throughout the process of increasing shear strain and approaches zero at the critical state, where the computed dilation angle ranges from $21^{\circ}-0^{\circ}$. Thus, the assumption of associated flow rule is not realistic based on the direct shear tests. Not surprisingly, it is generally recognized that the assumption of associated flow rule is not realistic in practice for drained stability of cohesive-frictional soil or effective stress analysis since this assumption gives rise to excessive volume change at the limit state for soils with high friction angles.

The concept of Davis [24] advocated by Sloan [13] is adopted here to evaluate the influence of a nonassociated flow rule on a stability problem. According to Davis [24], if a problem is not highly constrained in a kinematic sense such as a problem with a free ground surface or a semi-infinite domain, a nonassociated flow rule will not have a major influence on the limit load for frictional soils. Since a problem of soil slope resting on a relatively low interface friction plane has an inclined free surface, it follows from Davis's concept that a non-associated flow rule will has small influence on the limit load of this problem.

For a stability of soil block resting on a low interface friction plane, the gravity force is the driving force which causes the failure of a soil mass. For 3D displacement-based finite element analysis, the failure can be numerically simulated by a gravity loading method or by a toe-removal method. The numerical simulation of the former is to perform a step-by-step small increment of soil unit weight until failure but that of the latter is to perform a step-by-step small removal of toe width. Both methods would give comparable results of corresponding dimensionless variables at the limit state. However, a failure simulation by the toeremoval method does not accurately determine the stability number as a function of a given dimensions and slope angle of inclined soil block performed in the laboratory. This is because the result of this analysis will give a range of failure width of slope depending on a pre-defined width of toe-removal simulation, i.e. $W_{f}=15.10-15.20 \mathrm{~cm}$, where $0.10 \mathrm{~cm}$ is used as each width of a toe-removal simulation. On the other hand, the gravity loading method can be used to determine the stability number of the model with a given exact dimension performed in the laboratory and to conveniently perform series of parametric studies of dimensionless variables presented in a later section. Thus, this method is selected for the reasons of accuracy and convenience. Moreover, the method of gravity loading was successfully applied to solve several slope stability problems by finite element limit analysis $[8,13,25,26]$. Thus, this technique should be valid in 3D displacement-based finite element analysis to solve stability of soil block on low interface friction plane which is one of the slope stability problems.

In this research, a failure analysis was performed by means of the gravity loading method. The weight multiplier ( $\Sigma M$ stage) is increased automatically by the software such that the applied unit weight is equal to the input unit weight $\left(\gamma_{\text {input }}\right)$ multiplied by the applied $\Sigma$ Mstage value. The weight increment is simulated by the automatic load control of the iterative finite element procedure. The state of failure is defined by the convergence of $\Sigma$ Mstage to a certain value, or the $\Sigma$ Mstage value cannot be increased further during two successive calculation steps [27], giving rise to the failure value of $\Sigma M$ stagef Accordingly, the failure unit weight $\left(\gamma_{f}\right)$ is obtained by the product of $\Sigma M$ stage and the input unit weight $\left(\gamma_{\text {input }}\right)$, i.e.: 


$$
\gamma_{f}=\Sigma M \text { stage }_{\mathrm{f}} \times \gamma_{\text {input }}
$$

Figure 5 shows examples of solutions to the gravity loading analysis by plotting the relationship of the $\Sigma M$ stage value at each step versus the displacement of a selected point. It can be seen that the curve pattern of $\Sigma$ Mstage is similar to the classical load-displacement curve of the limit state analysis, such as the bearing capacity of the footing. The early portion of the curve has a nonlinear pattern, corresponding to the elastoplastic state or the contained plastic flow. As the limit state approaches the uncontained plastic flow, the curve tends to be flat and reaches a state of convergence. In particular, there is a significant increase in displacement with a small increment in the $\Sigma M$ stage value. It should be noted that the successful analysis of the gravity loading method has to be confirmed by the last portion of the curve where the state of convergence must be reached. Thus, the limit state is successfully solved and obtained.

Table 1 Normalized parameters of slip analysis without side supports.

\begin{tabular}{cccccccccc}
\hline \multicolumn{3}{c}{ Case study of width effect } & \multicolumn{3}{c}{ Case study of length effect } & \multicolumn{3}{c}{ Case study of thickness effect } \\
\hline \multirow{2}{*}{ No: } & $\begin{array}{c}\boldsymbol{\alpha} \\
\text { Degree }\end{array}$ & $\boldsymbol{L} / \boldsymbol{T}$ & $\boldsymbol{W} / \boldsymbol{T}$ & $\begin{array}{c}\boldsymbol{\alpha} \\
\text { Degree }\end{array}$ & $\boldsymbol{L} / \boldsymbol{T}$ & $\boldsymbol{W} / \boldsymbol{T}$ & $\begin{array}{c}\boldsymbol{\alpha} \\
\text { Degree }\end{array}$ & $\boldsymbol{L} / \boldsymbol{T}$ & $\boldsymbol{W} / \boldsymbol{T}$ \\
\hline 1 & 25 & 4 & 2 & 25 & 2 & 4 & 41 & 20.0 & 20.00 \\
2 & 25 & 4 & 3 & 28 & 3 & 4 & 35 & 13.33 & 13.33 \\
3 & 25 & 4 & 4 & 28 & 4 & 4 & 32 & 8.00 & 8.00 \\
4 & 25 & 4 & 5 & 26 & 5 & 4 & 31 & 6.67 & 6.67 \\
5 & 25 & 4 & 6 & 25 & 6 & 4 & 28 & 5.00 & 5.00 \\
6 & 25 & 4 & 8 & 25 & 8 & 4 & 25 & 4.00 & 4.00 \\
7 & 25 & 4 & 10 & 25 & 10 & 4 & 24 & 2.67 & 2.67 \\
8 & 25 & 4 & 12 & 25 & 12 & 4 & 23 & 2.00 & 2.00 \\
9 & 25 & 4 & 14 & 25 & 14 & 4 & 22 & 1.60 & 1.60 \\
10 & 25 & 4 & 16 & 25 & 16 & 4 & 21 & 1.14 & 1.14 \\
\hline
\end{tabular}

Table 2 Normalized parameters of slip analysis with side supports.

\begin{tabular}{ccccccc}
\hline & \multicolumn{2}{c}{ Case study of width effect } & \multicolumn{3}{c}{ Case study of length effect } \\
\hline No: & $\begin{array}{c}\boldsymbol{\alpha} \\
\text { Degree }\end{array}$ & $\boldsymbol{L} / \boldsymbol{T}$ & $\boldsymbol{W} / \boldsymbol{T}$ & $\begin{array}{c}\boldsymbol{\alpha} \\
\text { Degree }\end{array}$ & $\boldsymbol{L} / \boldsymbol{T}$ & $\boldsymbol{W} / \boldsymbol{T}$ \\
\hline 1 & 90 & 6 & 2 & 60 & 2 & 4 \\
2 & 75 & 6 & 3 & 59 & 3 & 4 \\
3 & 61 & 6 & 4 & 56 & 4 & 4 \\
4 & 52 & 6 & 5 & 54 & 5 & 4 \\
5 & 45 & 6 & 6 & 56 & 6 & 4 \\
6 & 41 & 6 & 8 & 60 & 8 & 4 \\
7 & 37 & 6 & 10 & 60 & 10 & 4 \\
8 & 37 & 6 & 12 & 57 & 12 & 4 \\
9 & 36 & 6 & 14 & 56 & 14 & 4 \\
& & & & 57 & 16 & 4 \\
\hline
\end{tabular}

Table 3 Input parameters for finite element analysis.

\begin{tabular}{lcc}
\hline Parameters & Unit & Value \\
\hline Drained type & - & Drained \\
Material model & - & Mohr-Coulomb \\
Unit weight, $\gamma$ & $\mathrm{kN} / \mathrm{m}^{3}$ & 25 \\
Young's modulus, $E$ & $\mathrm{kN} / \mathrm{m}^{2}$ & 4000 \\
Poisson's ratio, $\nu$ & - & 0.3 \\
Apparent cohesion, c & $\mathrm{kN} / \mathrm{m}^{2}$ & 0.358 \\
Friction angle, $\phi$ & $\circ$ & 41.5 \\
Dilatancy angle, $\psi$ & $\circ$ & 41.5 \\
Interface adhesion, $\mathrm{c}_{i}$ & $\mathrm{kN} / \mathrm{m}^{2}$ & 0.1 \\
Interface friction angle, $\phi_{i}$ & $\circ$ & 18.5 \\
\hline
\end{tabular}




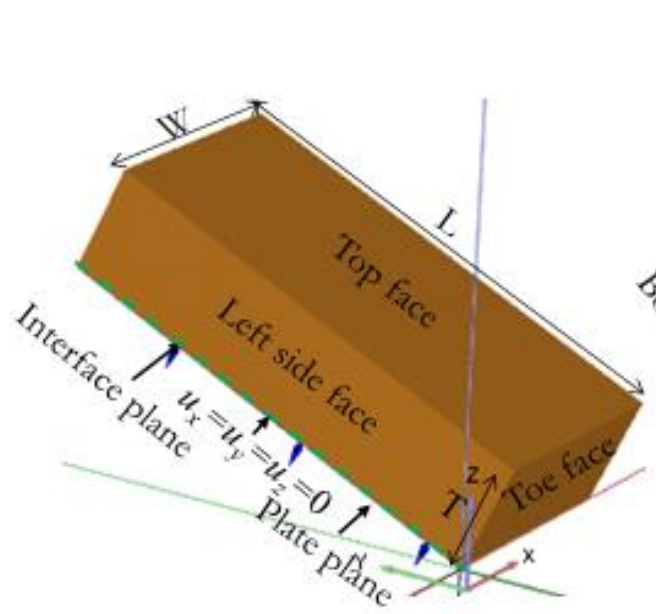

a) Geometry of slip analysis without side supports

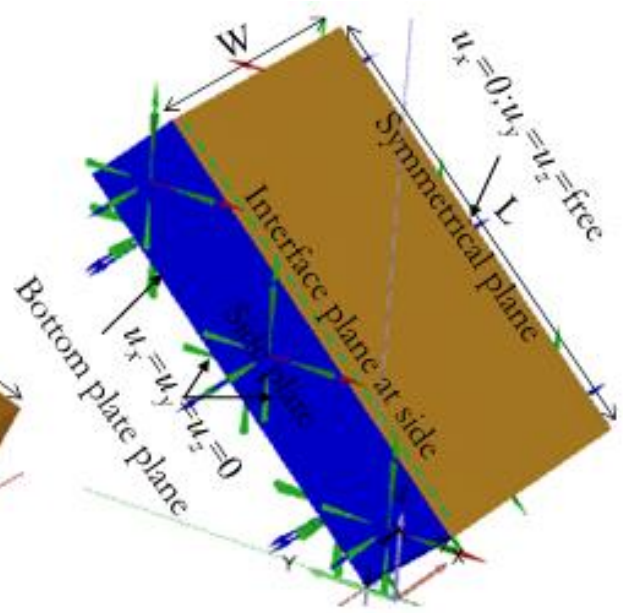

b) Geometry of slip analysis with side supports

Fig. 3. Geometry of numerical model of slip analyses without and with side supports.

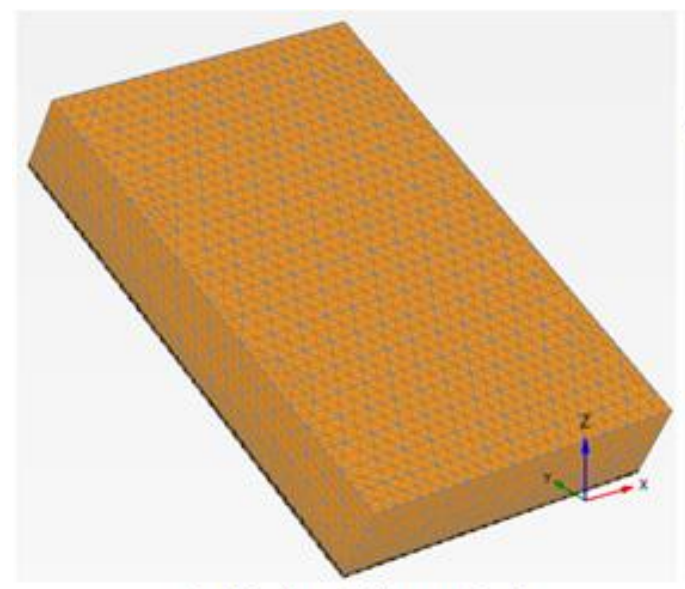

a) Mesh of slip analysis without side supports

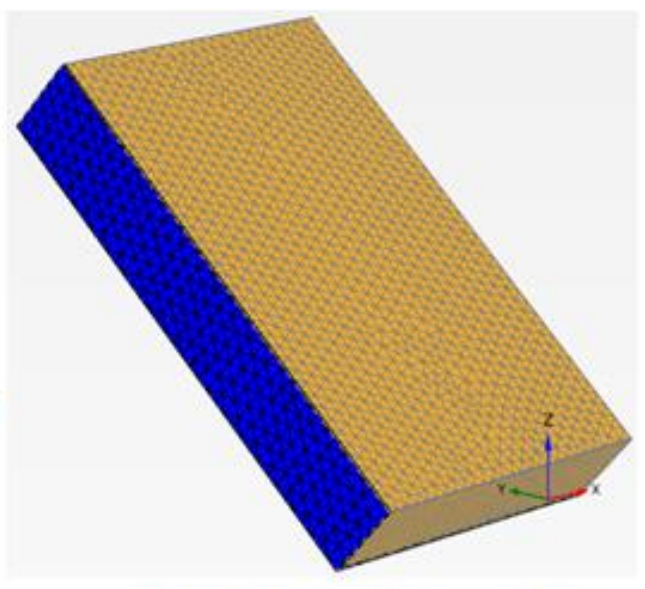

b) Mesh of slip analysis with side supports

Fig. 4. Examples of typical meshes used in the analyses.

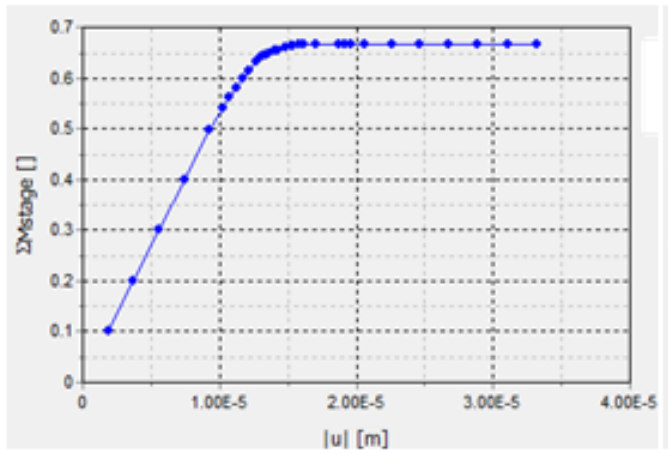

a) Slip analysis without side supports

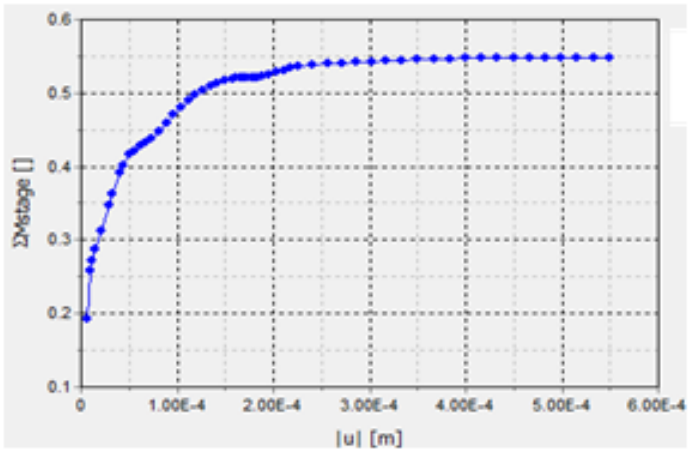

b) Slip analysis with side supports

Fig. 5. Examples of solutions to gravity loading method for failure analysis by Plaxis 3D. 


\section{Results of 3D Finite Element Analysis}

\subsection{Slip Analysis Without Side Supports}

Figure 1(a) also shows the free body diagram of a soil block, without side supports, resting on a low interface plane. The stability number of this problem can be calculated by utilizing the equilibrium of the forces parallel and normal to the slope. This is because the number of total unknowns is equal to the available equilibrium equations plus the equation arising from the Mohr-Coulomb failure criterion of the interface plane at the bottom, as summarized in Table 4. Thus, this problem is statically determinate, and the stability number of the slip analysis without side supports, $\gamma_{f} T / c_{i}$, can be obtained by the abovedescribed limit equilibrium method (LEM) [9] as:

$$
\frac{\gamma_{f} T}{c_{i}}=\frac{1}{\sin \alpha-\cos \alpha \tan \phi_{i}}
$$

Table 4. Number of unknowns and equations in slip analysis without side supports.

\begin{tabular}{ll}
\hline \multicolumn{1}{c}{ Unknowns } & \multicolumn{1}{c}{ Equations } \\
\hline$N_{\mathrm{b}}:$ Normal force on bottom plane & $\Sigma F_{t}=0$, equilibrium of force along inclined plane \\
$F_{r b}$ : Shear force on bottom plane & $\Sigma F_{n}=0 ;$ equilibrium of force normal to inclined plane \\
$\gamma_{f}$ Unit weight of soil at failure & $F_{b \mathrm{~b}}=\mathrm{N}_{\mathrm{b}}$ t $a n \phi_{i}+A_{b} \mathrm{c}_{\mathrm{i}}$; Mohr-Coulomb equation \\
\hline Total = 3 unknowns & Total $=3$ equations \\
\hline *Remarks: $A_{b}=$ area of bottom plane &
\end{tabular}

Figure 6 shows the stability number as a function of the width ratio for the case of the slip analysis without side supports for soil blocks with constant $0.05 \mathrm{~m}$ thick and $0.20 \mathrm{~m}$ long. All the results for the stability numbers of the 3-dimensional finite analysis match those of the limit equilibrium method in Eq. (2). However, the stability numbers of the two solutions are approximately twenty percent higher than those of the physical models. All the numerical and physical results indicate that the stability numbers are independent of the width of the soil block. Figure 7 shows an example of the failure mechanism predicted by the 3D finite element analysis of full model. The failure mechanism results, including the deformed mesh and the incremental displacement, indicate that the soil block slips downward and parallel to the underlying slip plane. In addition, the shear stress on the interface plane in Fig. 7(d) is fully mobilized to the shear strength of the interface, where the relative shear stress ratio of the interface is unity everywhere. However, the relative shear ratio of the soil block is smaller than unity for most of the soil, where some parts are close to unity. This indicates that the stress state of the soil block is still elastic with localized failure in some parts near the bottom plane.

Figure 8 shows a plot of the stability number versus the function of the length ratio for soil blocks with constant $0.05 \mathrm{~m}$ thick and $0.20 \mathrm{~m}$ wide, while comparisons of the failure mechanisms of the deformed meshes of different length ratios are shown in Fig. 9 for full model. It can be seen that the results of the finite element analysis are in good agreement with those of the limit equilibrium method for all cases of length ratios. The stability numbers of both predictions are 19 percent larger than those of the physical models. However, all of the numerical and physical results confirm that the failure is independent of any length of soil block. The failure mechanisms of the length effect are similar to those of the width effect. The soil block moves downward and parallel to the inclined plane. The results of the relative shear stresses on the interface and within the soil mass show behaviors similar to those described in the width effect. There is local failure in some parts of the soil block, where the stress state is below failure for almost the entire soil. However, the shear stresses on the interface plane are fully mobilized everywhere.

Figure 10 shows the stability numbers predicted by the 3D finite element analysis for the case of the thickness effect for soil blocks with constant $0.20 \mathrm{~m}$ wide and $0.20 \mathrm{~m}$ long. All the results from the finite element, the limit equilibrium and the physical models correspond rationally, especially for the trend of the curve. It can be observed that each stability number is inversely and nonlinearly proportional to the slope angle. The larger the slope angle, the smaller the stability number. Figure 11 shows the failure mechanisms of different slope angles for full model. Similarly, the failure of the system is caused by the downward movement of the soil block, where there is full mobilization of the relative shear stress ratios on the interface plane. 
Accordingly, all the results of the stability numbers of the 3D finite element analysis for the three cases of the slip analysis without side supports are in good agreement with those of the limit equilibrium method (LEM) by [9]. Therefore, it can be concluded that the method of the gravity loading analysis by Plaxis 3D is reliable in simulating the slip analysis without side supports. Even though there are some cases where the 3D finite element results for the stability numbers do not match those of the physical models, the effects of the length, the width and the thickness ratios on the stability numbers are simulated qualitatively with those of the physical models. In addition, the 3D finite element results confirm that the equation of the limit equilibrium method in (Eq. (2)) is valid for the soil block resting on a low interface friction plane.

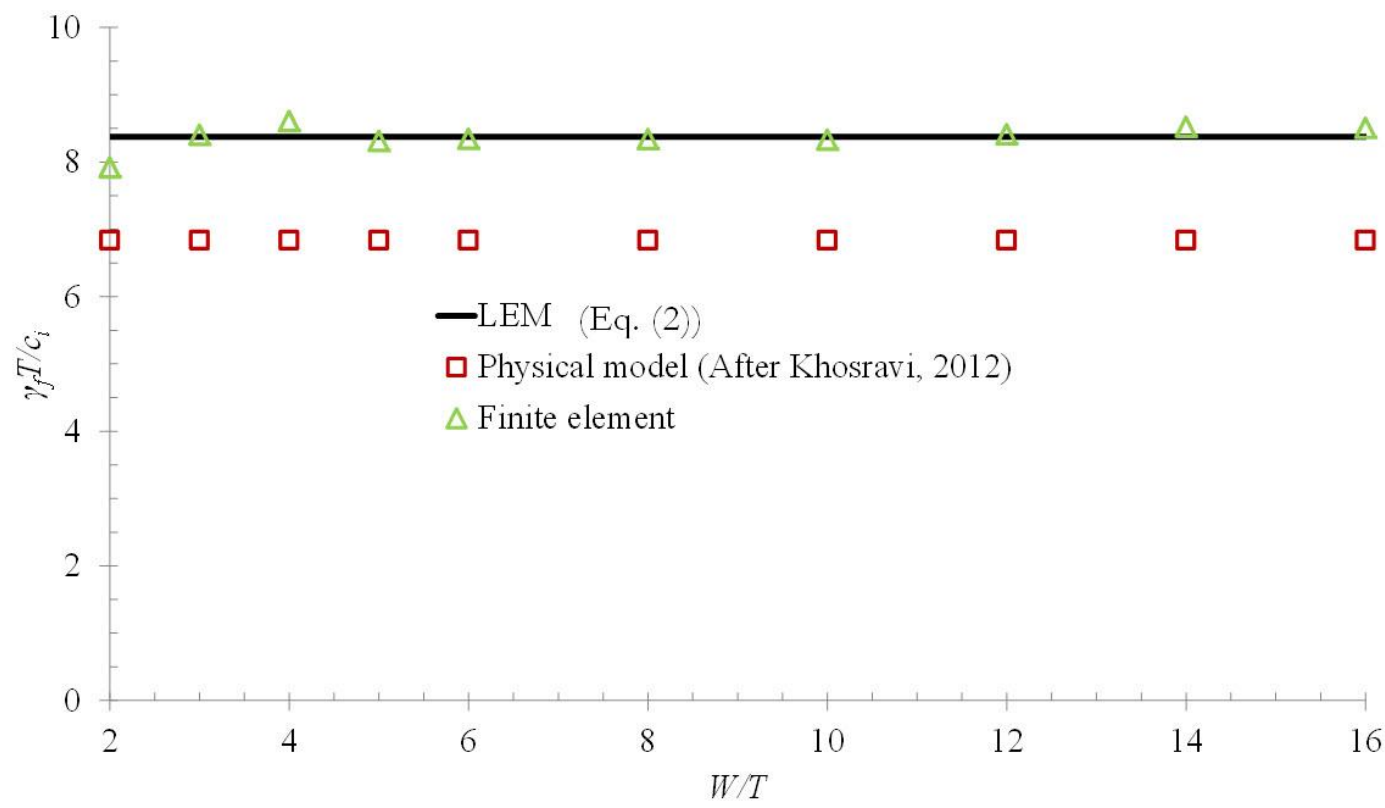

Fig. 6. Stability number versus width ratio of slip analysis without side supports for soil blocks with constant $0.05 \mathrm{~m}$ thick and $0.20 \mathrm{~m}$ long.

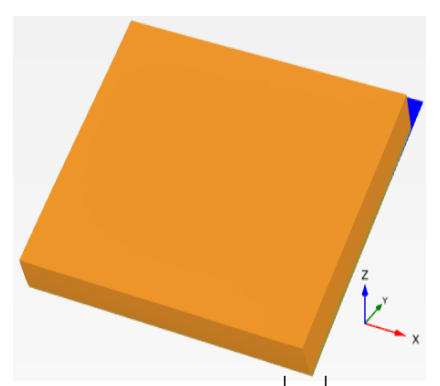

a) Deformed mesh , $|\mathrm{U}|$

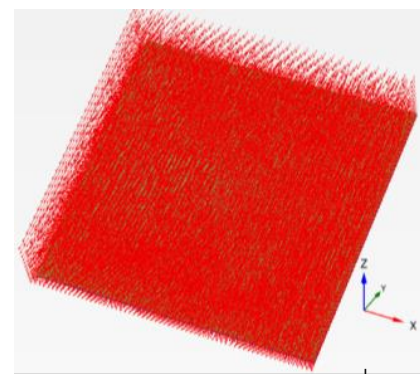

c) Incremental displacement, $|\Delta \mathrm{U}|$

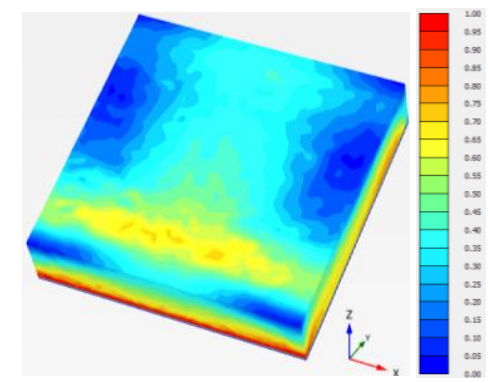

b) Relative shear stress of soil block, $\tau_{\text {rel }}$

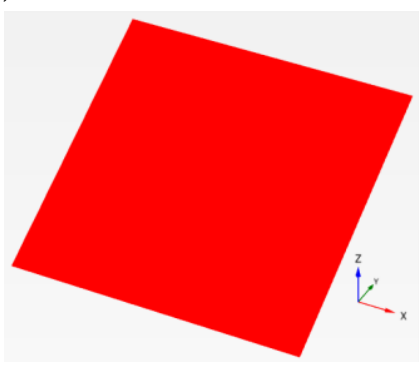

d) Relative shear stress of interface plane, $\tau_{\text {rel }}$

Fig. 7. 3D finite element results of slip analysis without side supports of full model where $\alpha=25^{\circ}$, $W / T=4$ and $L / T=4$. 


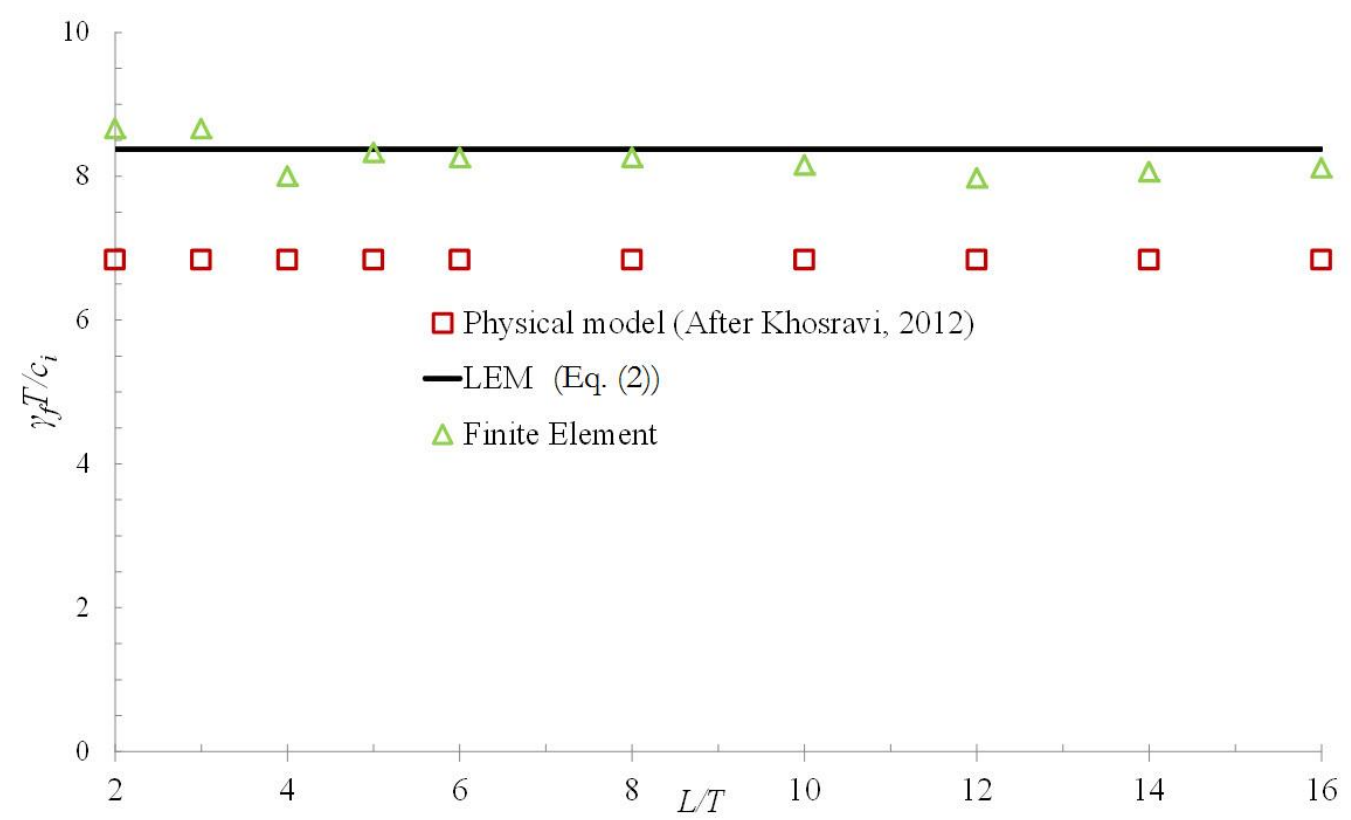

Fig. 8. Stability number versus length ratio of slip analysis without side supports for soil blocks with constant $0.05 \mathrm{~m}$ thick and $0.20 \mathrm{~m}$ wide.

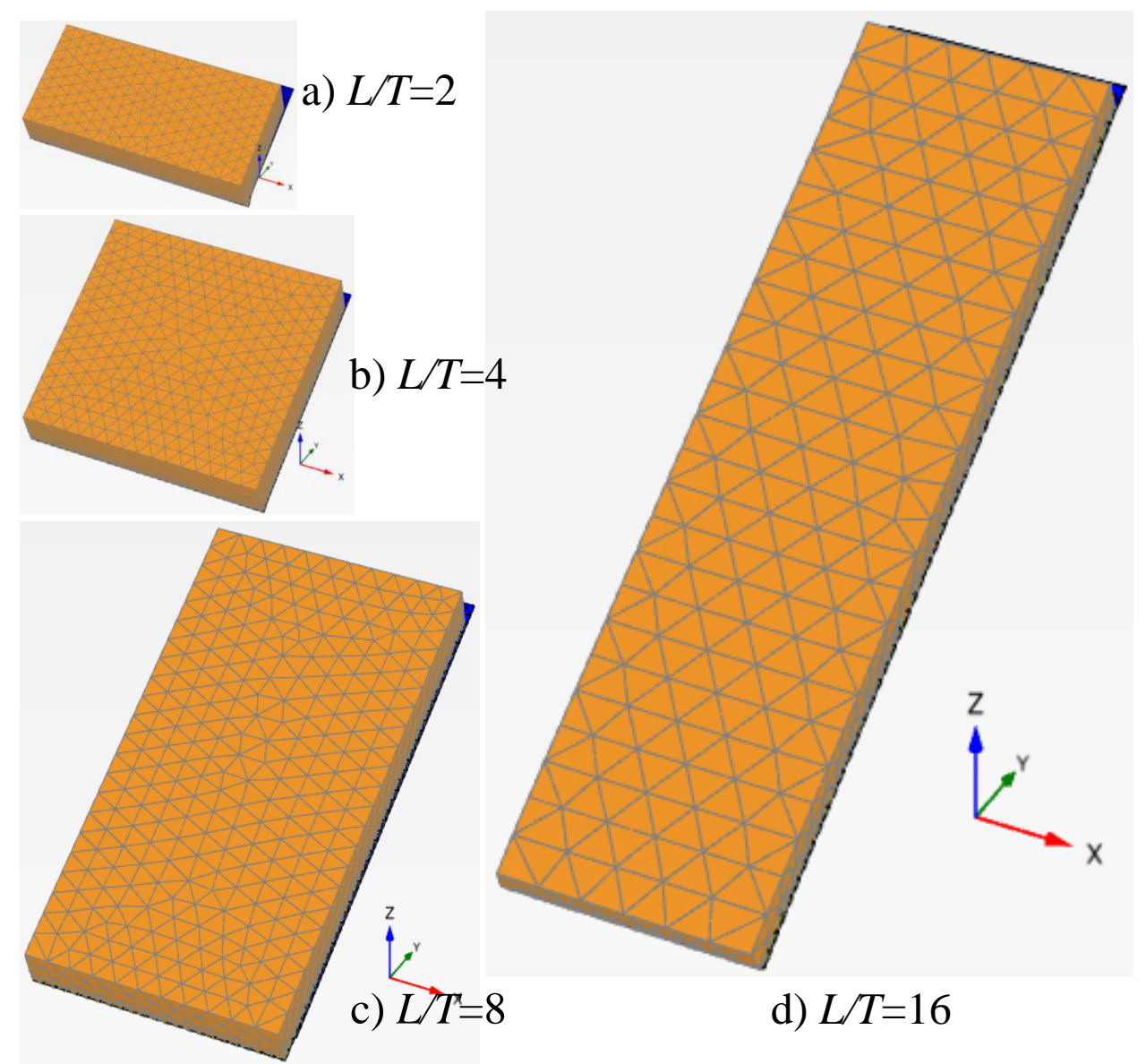

Fig. 9. Comparison of deformed meshes of slip analysis without side supports of full model, where $\alpha$ $=25^{\circ}, W / T=4$ and $L / T=2-16$. 


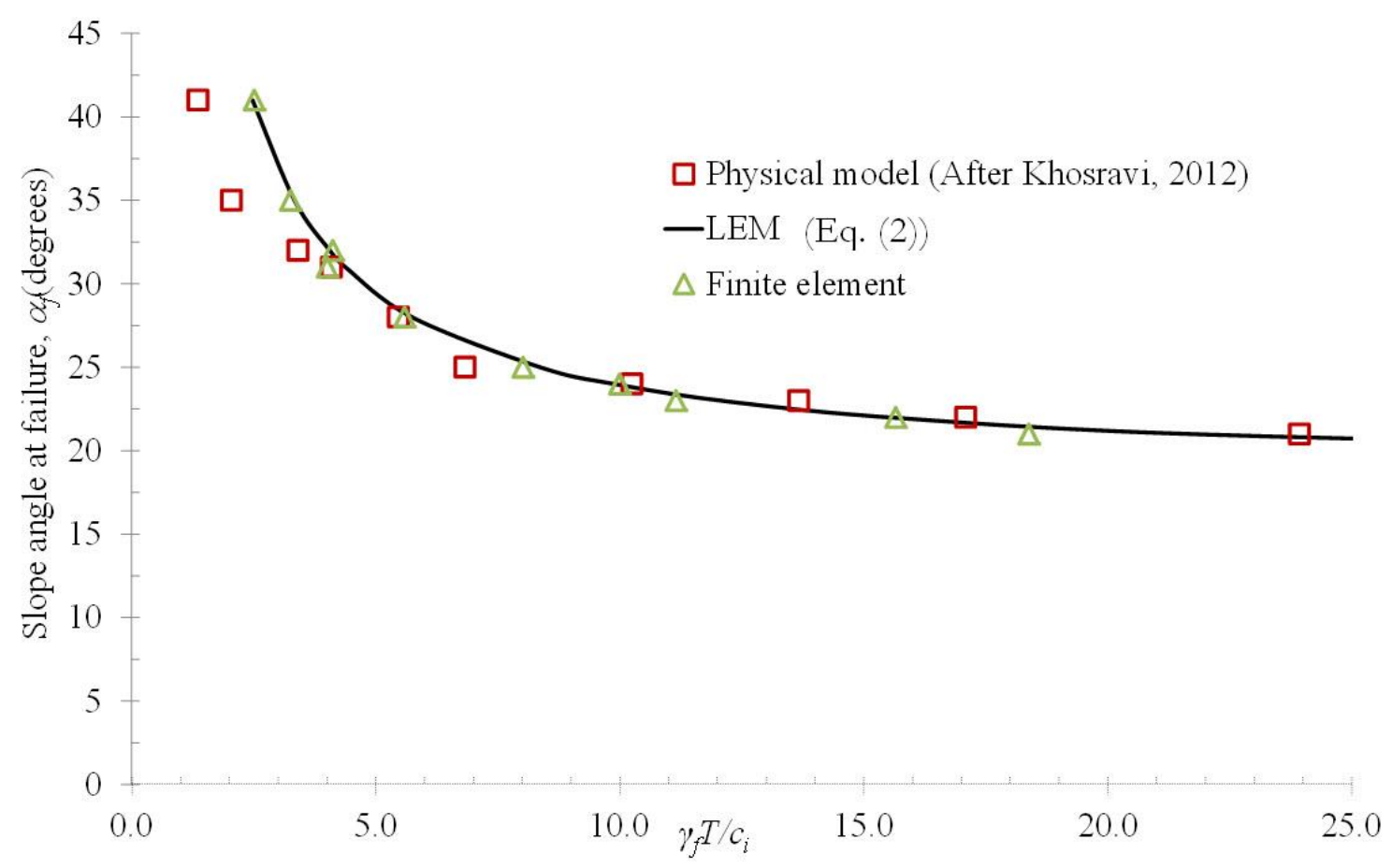

Fig. 10. Stability number versus slope angle of slip analysis without side supports for soil blocks with constant $0.20 \mathrm{~m}$ wide and $0.20 \mathrm{~m}$ long.

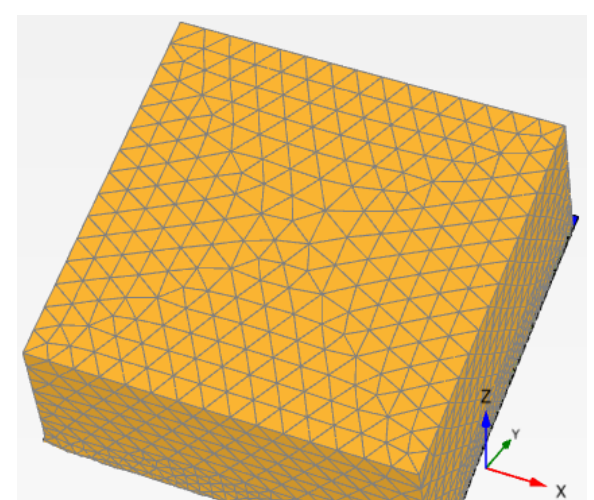

a) $\alpha=23^{\circ}$

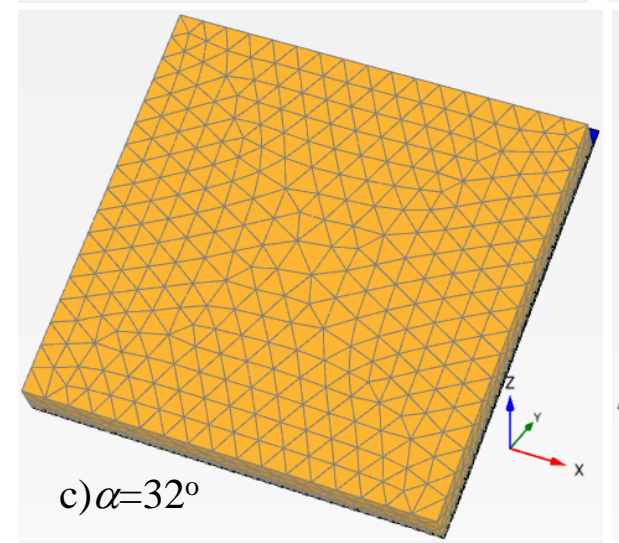

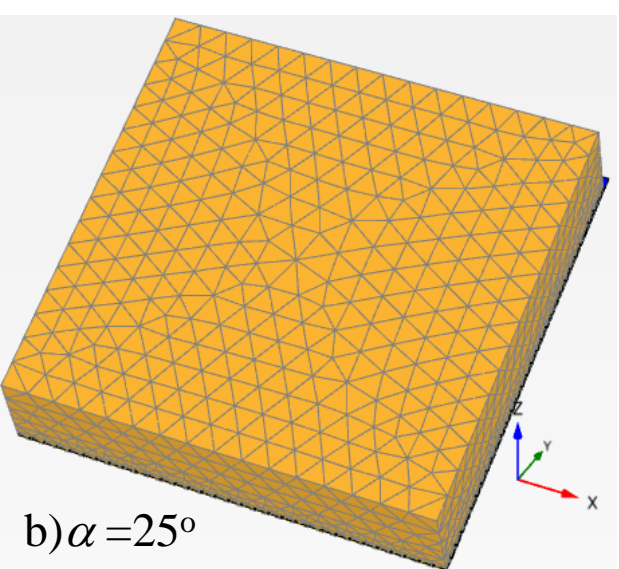

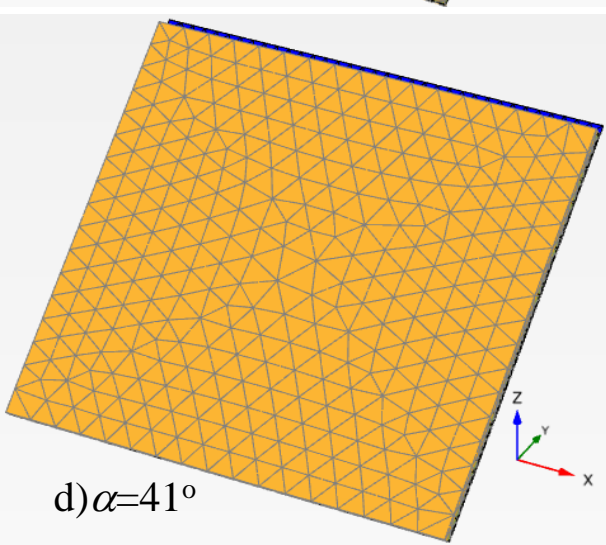

Fig. 11. Comparison of deformed meshes of slip analysis without side supports of full model, where $L / T=2-20$ and $W / T=2-20$. 


\subsection{Slip Analysis With Side Supports}

Figure 1(b) also shows a free body diagram of a soil block resting on an inclined plane, which is fully supported on both sides. In this case, the stability number of this problem cannot be solved by the classical limit equilibrium method utilizing the equilibrium of forces parallel and normal to the slope. The number of total unknowns is greater than the available equilibrium equations plus the equations arising from the Mohr-Coulomb failure criterion of the interface plane at the bottom and at the side, as summarized in Table 5. Thus, the problem is statically indeterminate. When the soil block is fully supported at both ends, an additional assumption is required in order to render the problem statically determinate. The assumption of the circular arch action of the hopper, developed by [28], can be applied to solve the stress state for the slip analysis with side supports. Based on the limit equilibrium of the stress along the arch, derived by [9], the relationship between the soil width and the failure unit weight of the slip analysis with side supports can be obtained as:

$$
W=\frac{\cos \phi}{\left(\frac{\sin \left(\alpha-\phi_{i}\right)}{\cos \phi_{i}}-\frac{c_{i}}{\gamma_{f} T}\right)} \frac{\sigma_{c}}{\gamma_{f}}
$$

where, $\sigma_{c}$ is the unconfined compressive strength of the soil; i.e.,

$$
\sigma_{c}=2 c \tan \left(45+\frac{\phi}{2}\right)
$$

Figure 12 shows the effect of the slope angle on the modified stability number, $\gamma_{f} W / \mathrm{c}_{\mathrm{i}}$ of the slip analysis with side supports. In this figure, the term $\gamma_{f} W / \mathrm{c}_{\mathrm{i}}$ is used instead of $\gamma_{f} T / \mathrm{c}_{\mathrm{i}}$, since both the slope angle and the soil width were varied, but the soil thickness and length were kept constant to $0.05 \mathrm{~m}$ and $0.30 \mathrm{~m}$, respectively. The results show that stability number $\gamma_{f} W / \mathrm{c}_{\mathrm{i}}$ is nonlinear and inversely proportional to the slope angle. The finite element solutions match those of the physical models acceptably. However, the limit equilibrium solutions agree with those of the physical models for the case of a gentle angle, but underpredict the stability number for the case of a steep angle. Figure 13 shows the predicted failure mechanisms for case \#6 of half model, where $\alpha=41^{\circ}, L / T=6$ and $W / T=8$. There is large incremental displacement of the soil block at the center, which gradually decreases to both sides (Fig. 13(a)). The relative shear stresses are fully mobilized to their shear strengths for the soil block as well as the bottom and side interface plane (Fig. 13(c, d and e)). This result indicates that the failure is caused by sliding along the bottom and side plane (Fig. 13(d and e)) as well as the failure of the soil block (Fig. 13(c)). Moreover, the direction of the major principal stress of the soil block indicates that stresses are transmitted to the side supports. This behavior is similar to the arching theory of the limit equilibrium method (LEM) proposed by [21].

Figure 14 shows a plot of the stability number versus the model length ratio for soil blocks with constant $0.05 \mathrm{~m}$ thick and $0.20 \mathrm{~m}$ wide. The stability numbers of the finite element analysis are slightly lower than those of the physical models for all cases of length ratios. However, those of the limit equilibrium method are significantly lower than those of the physical models. All of the numerical and physical results confirm that the failure is independent of any length of the soil block. Figure 15 shows the predicted failure mechanism from the finite element analysis of half model for the cases of the length effect with $W / T=4$. The failure mechanisms of the length effect are similar to those of the width effect. The soil block moves downward and parallel to the bottom plane, where full mobilization occurs at the bottom interface and side interface.

Based on the agreeable agreements between the results of the 3D finite element analysis and those of the physical models, it can be concluded that the method of the gravity loading analysis by Plaxis 3D is also reliable for use in the slip analysis with side supports. Even though there are some cases where the 3D finite element results of the stability number do not match those of the physical models, the effects of the slope angle, the length and the width ratios on the stability number are simulated qualitatively with those of the physical models. In addition, the 3D finite element results indicate that the expression of the stability number from the limit equilibrium of this case (Eq. (3)) can be applied only for gentle slope angles. 


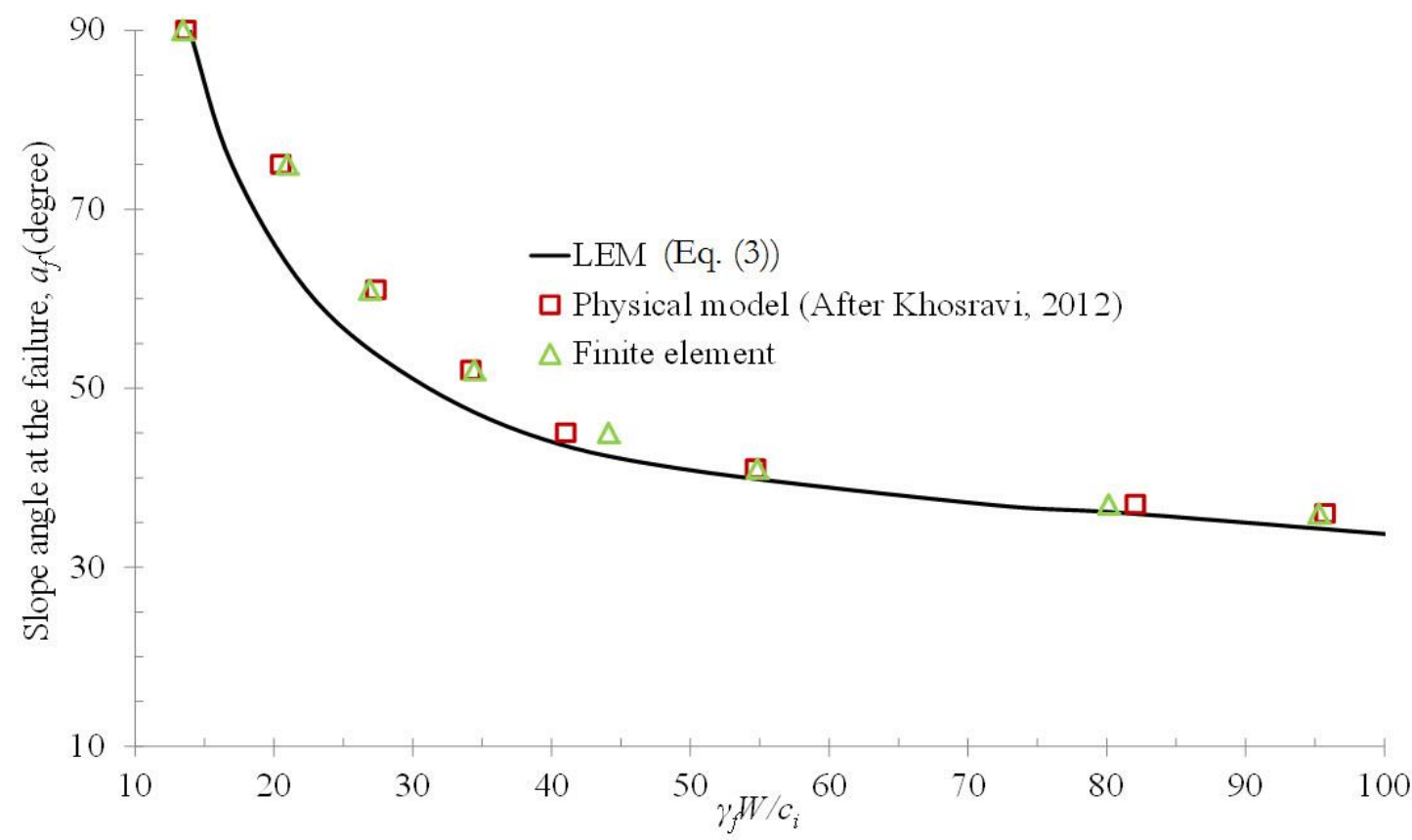

Fig. 12. Effect of slope angle on stability number of slip analysis with side supports for soil blocks with constant $0.05 \mathrm{~m}$ thick and $0.30 \mathrm{~m}$ long.

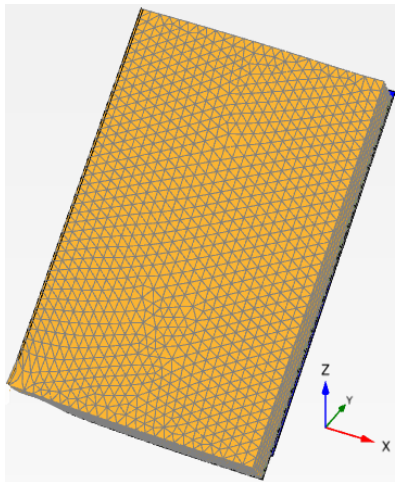

a) Deformed mesh, $|\mathrm{u}|$

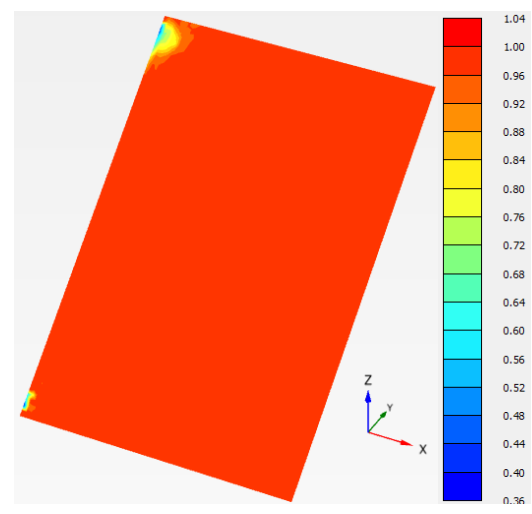

d) Relative shear stress on interface plane, $\tau_{\text {rel }}$

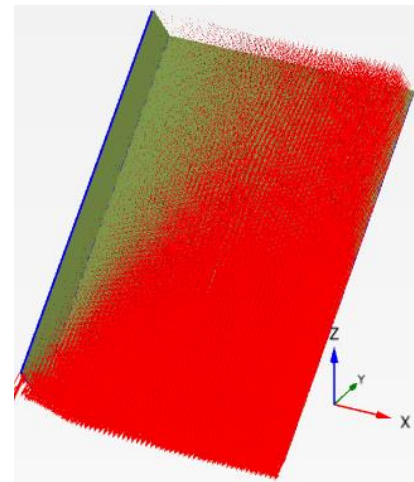

b) Incremental displacement, $\mid \Delta \mathrm{U}$

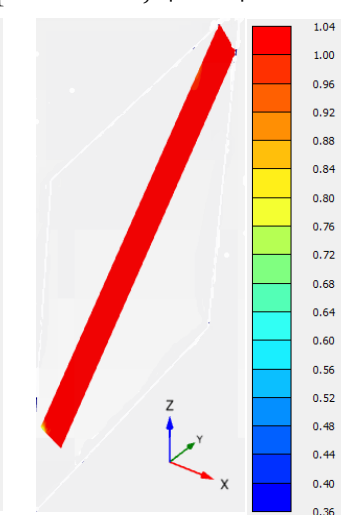

e) Relative shear stress on side plane, $\tau_{\text {rel }}$

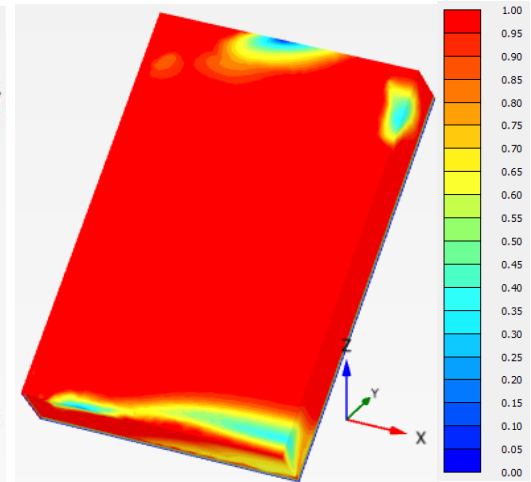

c) Relative shear stress of soil block, $\tau_{\text {rel }}$

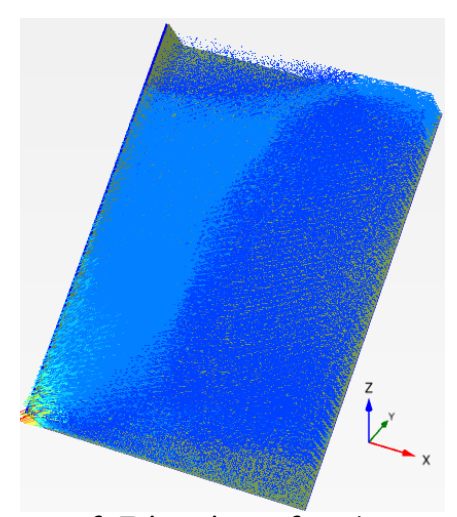

f) Direction of major principal stress, $\sigma_{1}$

Fig. 13. Finite element results of slip analysis with side supports of half model, where $\alpha=41^{\circ}, L / T=6$ and $W / T=8$ 


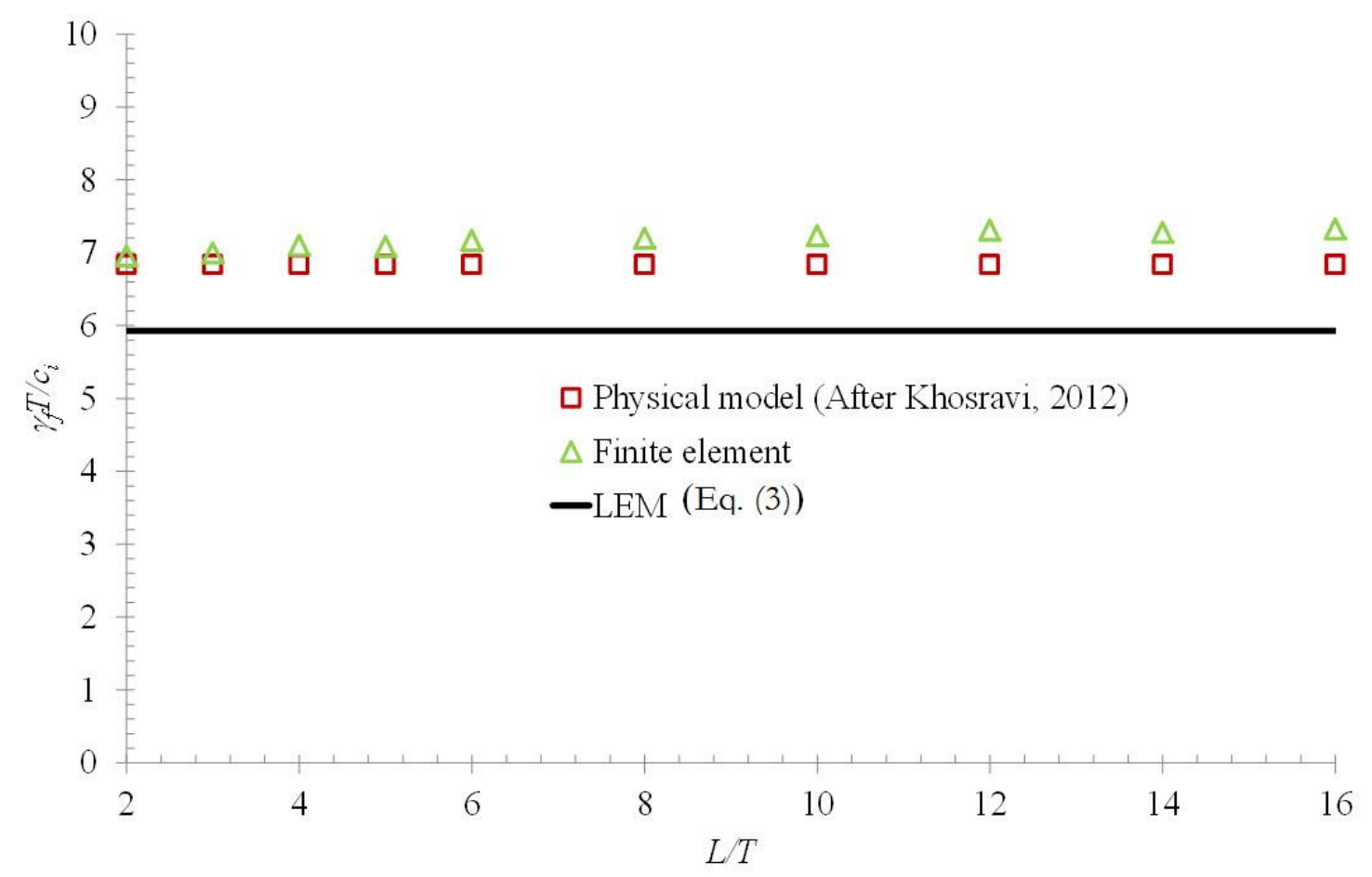

Fig. 14. Effect of length ratio on stability number of slip analysis with side supports for soil blocks with constant $0.05 \mathrm{~m}$ thick and $0.20 \mathrm{~m}$ wide

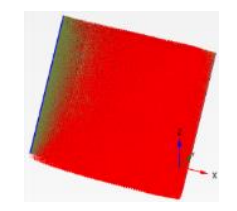

a) $L / T=2$

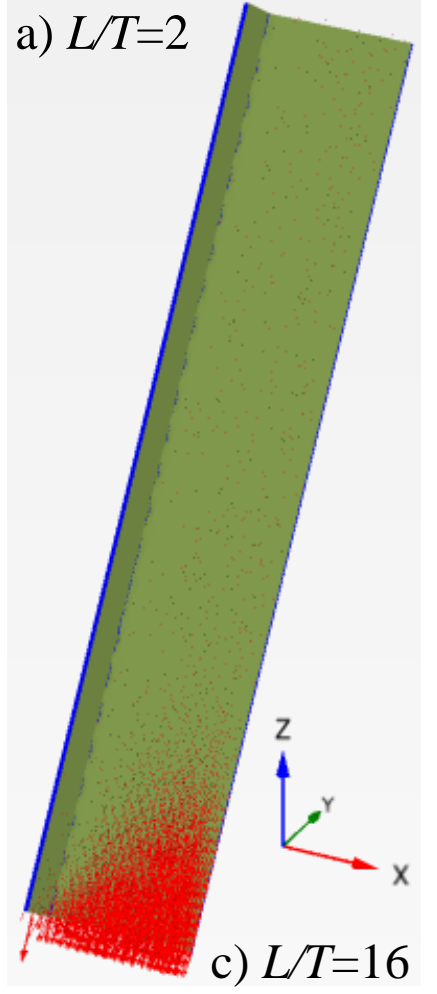

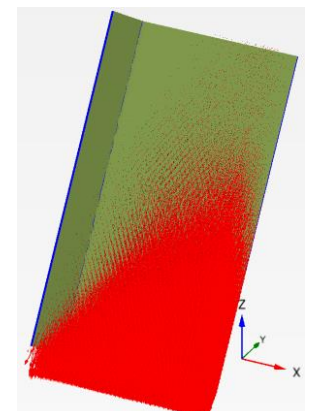

b) $L / T=4$

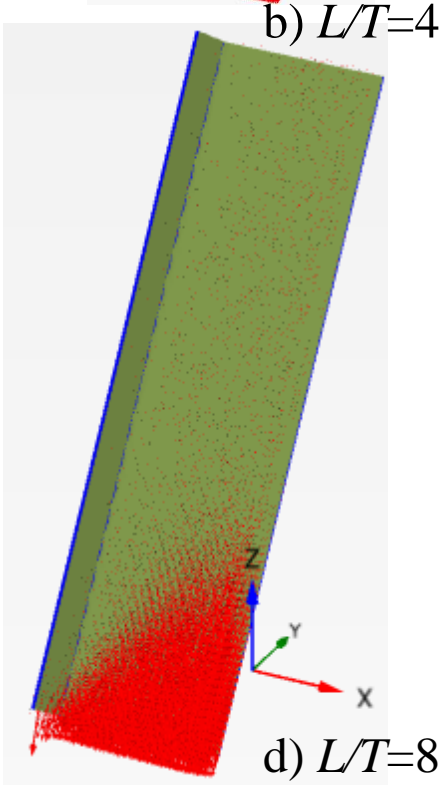

Fig. 15. Comparison of incremental displacement of slip analysis with side supports of half model for different length ratios with $W / T=4$. 
Table 5. Number of unknowns and equations of slip analysis with side supports.

\begin{tabular}{l|l}
\hline \multicolumn{1}{c|}{ Unknowns } & \multicolumn{1}{c}{ Equations } \\
\hline$N_{b}:$ Normal force on bottom plane & $\sum F_{t}=0$, equilibrium of force along inclined plane \\
$F_{r b}:$ Shear force on bottom plane & $\sum F_{n}=0$, equilibrium of force normal to inclined plane \\
$N_{s}:$ Normal force on side plane & $F_{b}=N_{b} \tan \phi_{t}+A_{b} \mathrm{c}_{\mathrm{i}}$, Mohr-Coulomb equation of bottom plane \\
$F_{r s}$ Shear force on side plane & $F_{r s}=N_{s} \tan \phi+A_{s} \mathrm{c}$, Mohr-Coulomb equation of side plane \\
$\gamma_{\mathrm{f}: \text { Unit weight of soil at failure }}$ & \multicolumn{1}{c}{ Total = 4 equations } \\
\hline Total=5 unknowns &
\end{tabular}

$*$ Remark: $A_{s}=$ area of side plane

\section{Parametric Studies of Slip Analysis With Side Supports}

This section presents extensive parametric studies of the finite element analysis of the slip analysis with side supports, which will be used to develop the curve fitting equation for predicting the stability number of this problem. For the case of the slip analysis with side supports, the stability number depends on seven dimensional variables, including $T, W, \mathrm{c}, \mathrm{c}_{\mathrm{i}}, \alpha, \phi$ and $\phi_{\text {i }}$. The technique of dimensional analysis [29, 30] was employed to reduce the number of parameters and to make the problem less complicated. As a result, the stability number of this problem is a function of four independent normalized parameters of the dimensionless group, as follows:

$$
y=f\left(x_{1}, x_{2}, x_{3}, x_{4}\right)
$$

where, $y=\frac{\gamma_{f} T}{c_{i}}$, stability number; $x_{1}=T / W$, thickness to width ratio; $x_{2}=\mathrm{c} / \mathrm{c}_{\mathrm{i}}$, ratio of soil apparent cohesion to interface apparent cohesion; $x_{3}=\tan \left(45^{\circ}+\phi / 2\right)$; Function of soil friction angle; $x_{4}=\frac{\cos \phi_{i}}{\sin \left(\alpha-\phi_{i}\right)}$, Combined effect of interface friction and slope angle.

It should be noted that normalized parameter $x_{4}$ is obtained from observations of the stability number of the slip analysis without side supports based on the limit equilibrium, Eq. (2). As explained in the previous section, it is concluded that Eq. (2) is reasonably valid since the stability number of LEM and the 3D finite element analysis match each other exactly for all parametric studies. Thus, normalized parameter $x_{4}$ is obtained by rewriting Eq. (2) for the stability number of the slip analysis without side supports as:

$$
\frac{\gamma_{f} T}{c_{i}}=\frac{\cos \phi_{i}}{\sin \left(\alpha-\phi_{i}\right)}
$$

For the case of the slip analysis with side supports, it is expected that the stability number should still depend on $x_{4}$ in addition to $x_{1}-x_{3}$. The stability number of the slip analysis with side supports becomes that without side supports when the width of the former is significantly wide or mathematically approaches infinity.

In order to develop the curve fitting equation of the slip analysis with side supports, parametric studies of parameters $x_{1}, x_{2}, x_{3}$ and $x_{4}$ are carried out extensively, while the interface apparent cohesion of $0.1 \mathrm{kPa}$ and the interface friction angle of $18.5^{\circ}$ are kept constant. For those studies, four different values for each normalized parameter are varied as follows: 1) $\left.x_{1}=T / W=0.1,0.167,0.2,0.25 ; 2\right) x_{2}=\mathrm{c} / \mathrm{c}_{1}=2.5,3.58$, 7.16, 10.14; and normalized parameters for $x_{3}$ and $x_{4}$ are generated by changing the slope angle to $\alpha=33^{\circ}$, $40^{\circ}, 46^{\circ}$ and $55^{\circ}$, as well as the soil friction angle to $\phi=20^{\circ}, 25^{\circ}, 30^{\circ}$ and $41.6^{\circ}$, respectively. As a result, the range in parameters $x_{3}$ and $x_{4}$ are $x_{3}=1.428,1.570,1.732$ and 2.220 and $x_{4}=1.594,2.054,2.588$ and 3.788 . Thus, 256 simulations for the 3D finite element were analyzed for this problem. Figure 16 shows the stability number, $\gamma_{f} T / c_{i}$ as a function of $x_{1}=T / W$, where $x_{2}=2.5$ and 3.788 and $x_{4}=1.594$ and 10.14. It can be observed that the stability number, $\gamma_{f} T / \mathrm{c}_{\mathrm{i}}$ is a nonlinear function of $x_{1}=T / W$ for given values of $x_{2}, x_{3}$ and $x_{4}$. The larger the ratio for $x_{1}$ is, the higher the stability number will be. Ideally, stability number $\gamma_{f} T / \mathrm{c}_{\mathrm{i}}$ converges to $x_{4}$ when $x_{1}$ approaches zero. 
Figure 17 shows stability number $\gamma_{f} T / \mathrm{c}_{\mathrm{i}}$ as a function of $x_{2}=\mathrm{c} / \mathrm{c}_{\mathrm{i}}$, where $x_{1}=0.1$ and 0.25 and $x_{4}=$ 1.594 and 3.788. It can be observed that stability number $\gamma_{f} T / \mathrm{c}_{\mathrm{i}}$ is a linear function of $x_{2}=\mathrm{c} / \mathrm{c}_{\mathrm{i}}$ for given values of $x_{1}, x_{3}$ and $x_{4}$. The slope values of those linear trend lines depend on the normalized parameters, $x_{1}$, $x_{3}$ and $x_{4}$, where their intercept points do not always pass the origin.

Figure 18 shows plot stability number $\gamma_{f} T / c_{i}$ as a function of $x_{3}=\tan \left(45^{\circ}+\phi / 2\right)$, where $x_{1}=0.1$ and 0.25 and $x_{2}=2.5$ and 10.74. It can be observed that there is also a nonlinear relationship between $\gamma_{f} T / \mathrm{c}_{\mathrm{i}}$ and $x_{3}$, where the nonlinear trend lines do not pass the origin point. The larger the soil friction angle is, the higher the stability number will be.

Figure 19 shows stability number $\gamma_{f} T / c_{i}$ as a function of $x_{4}=\frac{\cos \phi_{i}}{\sin \left(\alpha-\phi_{i}\right)}$, where $x_{i}=0.1$ and 0.25 and $x_{2}=2.5$ and 10.14. It can be observed that the stability number is a linear function of $x_{4}$. The higher the value of $x_{4}$ is, the higher the stability number will be. All linear trend lines between $\gamma_{f} T / \mathrm{c}_{\mathrm{i}}$ and $x_{4}$ pass the origin point, but their slopes depend on normalized parameters $x_{1}, x_{2}$ and $x_{3}$.

Based on observation results in Figs. 16-19, the empirical expression for stability number $\gamma_{f} T / \mathrm{c}_{\mathrm{i}}$ of the slip analysis with side supports is proposed as follows:

$$
y=\frac{\gamma_{f} T}{c_{i}}=\left(A_{1} \sqrt{x_{1}} x_{2} \sqrt{x_{3}}+A_{2} \sqrt{x_{1}} x_{2} x_{3}+A_{3} x_{1} x_{2} \sqrt{x_{3}}+A_{3} x_{1} x_{2} x_{3}+1\right) x_{4}
$$

where, $A_{1}-A_{4}=$ Empirical constants.

It should be noted that there are four empirical constants for the proposed expression, where the stability number is obtained from the summation of the product of the linear term, $x_{2}$, and the nonlinear terms, $x_{1}$ and $x_{3}$. In addition, the proposed stability number in Eq. (7) has a linear relationship with $x_{4}$, where the linear expression line passes the origin point and its slope depends on normalized parameters $x_{1}$ $x_{3}$. When $x_{1}=0$, this ideal case corresponds to the slip analysis without side supports. Equation (7) yields $y=\frac{\gamma_{f} T}{c_{i}}=x_{4}$, which corresponds to the observed results mentioned earlier.

A statistical approach of curve fitting [31, 32] was applied to determine the four empirical constants of the proposed equation. In this approach, the optimal set of four constants is obtained by minimizing the residual sum of the squares between the stability number of the finite element analysis and those of the proposed equation in Eq. (7). The residual sum of the squares, $S S_{\text {res }}$, has the following expression:

$$
S S_{\text {RES }}=\sum_{i=1}^{n}\left(f_{i}-y_{i}\right)^{2}
$$

where $f_{i}=$ Stability number from the finite element data; $y_{i}=$ Stability number from Eq. (7); $\mathrm{n}=$ Number of data $=256$.

The technique of curve fitting leads to a least squares type of problem, where the residual sum of the squares between the data and the corresponding prediction is minimized. The final results of the optimal set of four constants by the least squares optimization problem are summarized in Table 6 .

Table 6. Optimal values of empirical constants.

\begin{tabular}{cccc}
\hline $\mathbf{A}_{1}$ & $\mathbf{A}_{2}$ & $\mathbf{A}_{3}$ & $\mathbf{A}_{4}$ \\
\hline-0.218873 & -0.199914 & 1.42733 & 1.65653 \\
\hline
\end{tabular}

In statistics, the coefficient of determination, $\mathrm{R}^{2}$, is a number that indicates how well the data fit in the statistical model, and it can be calculated by the following equation as:

$$
R^{2}=\left(1-\frac{R R_{r e s}}{R R_{t o t}}\right)
$$

where $R_{t o t}=\sum(y-\bar{y})^{2}$, the total sum of squares.

The value of the coefficient of determination is between 0 and $100 \%$. The closer $\mathrm{R}^{2}$ is to $100 \%$, the better the fit of the model will be. Figure 20 shows a comparison of the stability number between the proposed equation (Eq. (7)) and the finite element analysis. It can be seen that the stability number of the 
proposed equation obviously agrees well with those of the finite elements, where the coefficient of determination, $\mathrm{R}^{2}$, is very high at $99.54 \%$ based on 256 pieces of data from parametric studies.

For the special case of zero apparent interface adhesion, the proposed Eq. (7) can be rewritten as the modified stability number, which is calculated based on the apparent soil cohesion as:

$$
z=\frac{\gamma_{f} T}{c}=x_{4}\left[\left(A_{1} \sqrt{x_{3}}+A_{2} x_{3}\right) \sqrt{x_{1}}+\left(A_{3} \sqrt{x_{3}}+A_{4} x_{3}\right) x_{1}\right]
$$

where, $z=\frac{\gamma_{f} T}{c}=$ modified stability number.
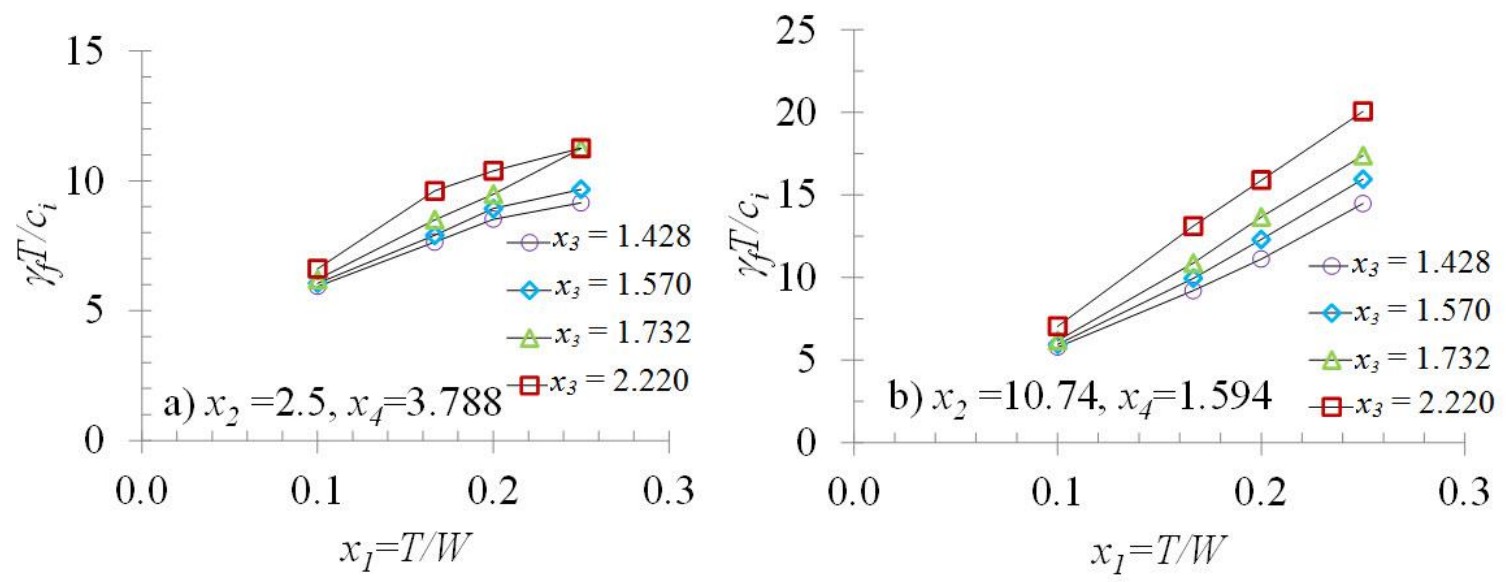

Fig. 16. Influence of parameter $x_{1}=T / W$ on stability number of slip analysis with side supports.
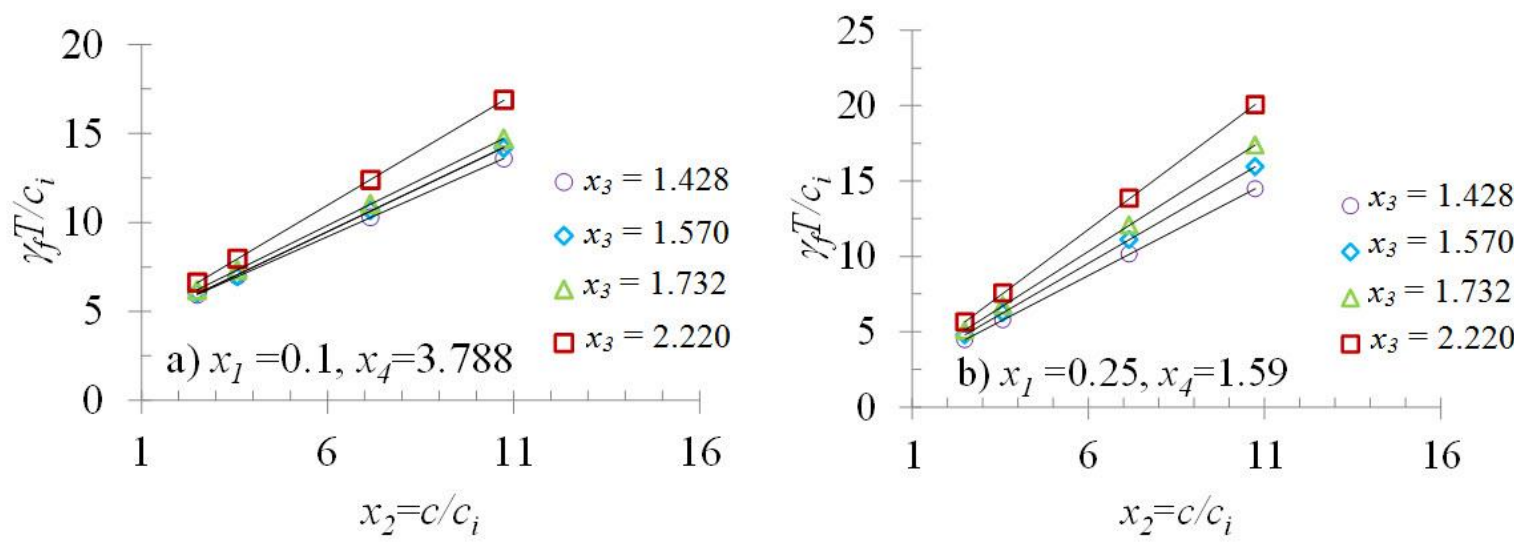

Fig. 17. Influence of parameter $x_{2}=\mathrm{c} / \mathrm{c}_{\mathrm{i}}$ on stability number of slip analysis with side supports.
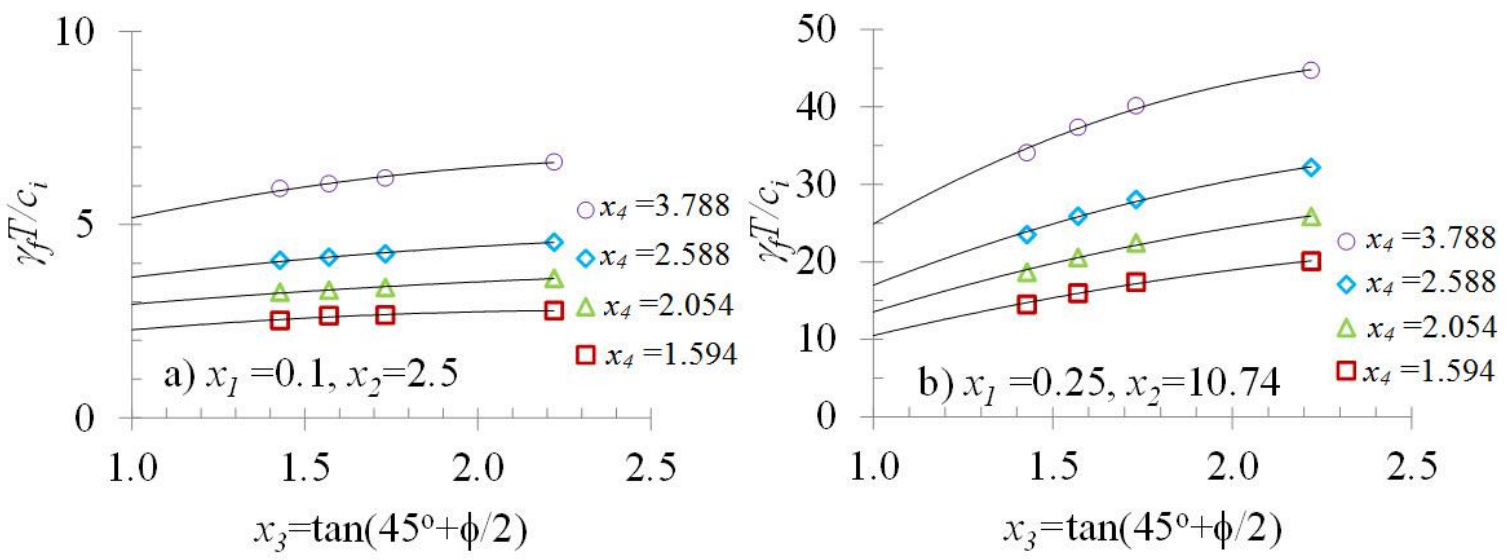

Fig. 18. Influence of parameter $x_{3}=\tan \left(45^{\circ}+\phi / 2\right)$ to stability number of slip analysis with side supports. 

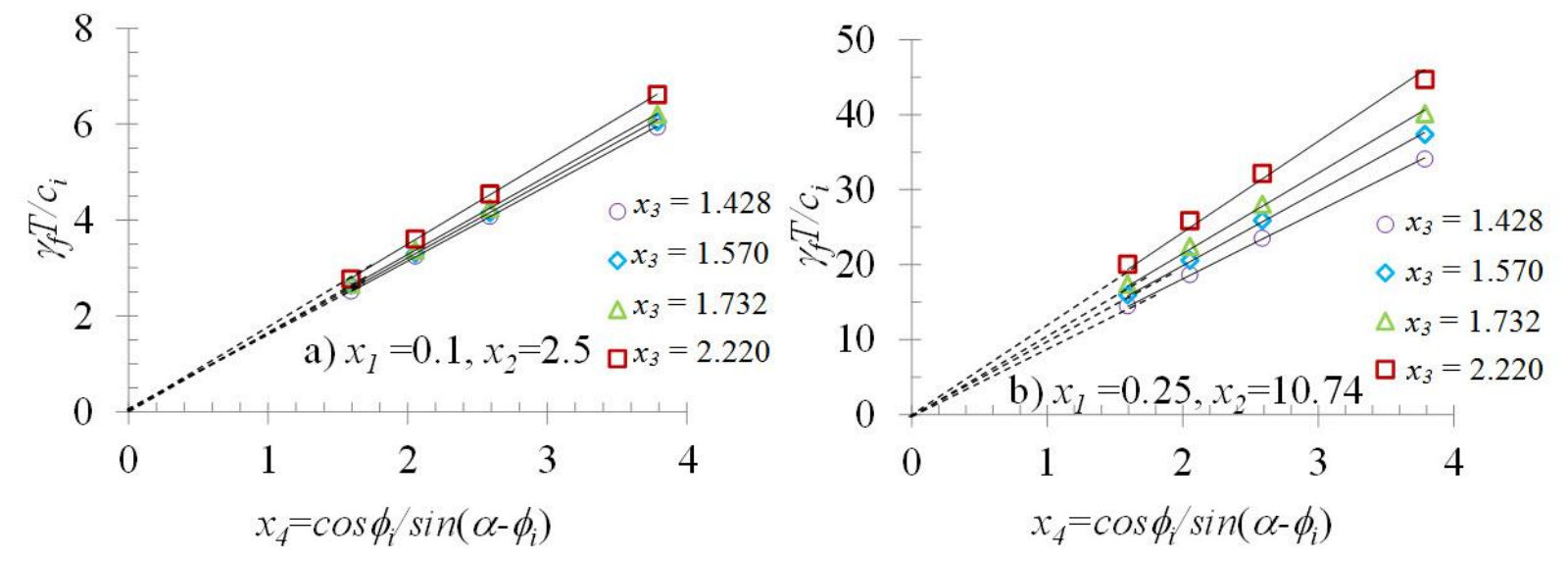

Fig. 19. Influence of parameter $x_{4}=\cos \phi_{i} / \sin \left(\alpha-\phi_{i}\right)$ to stability number of slip analysis with side supports.

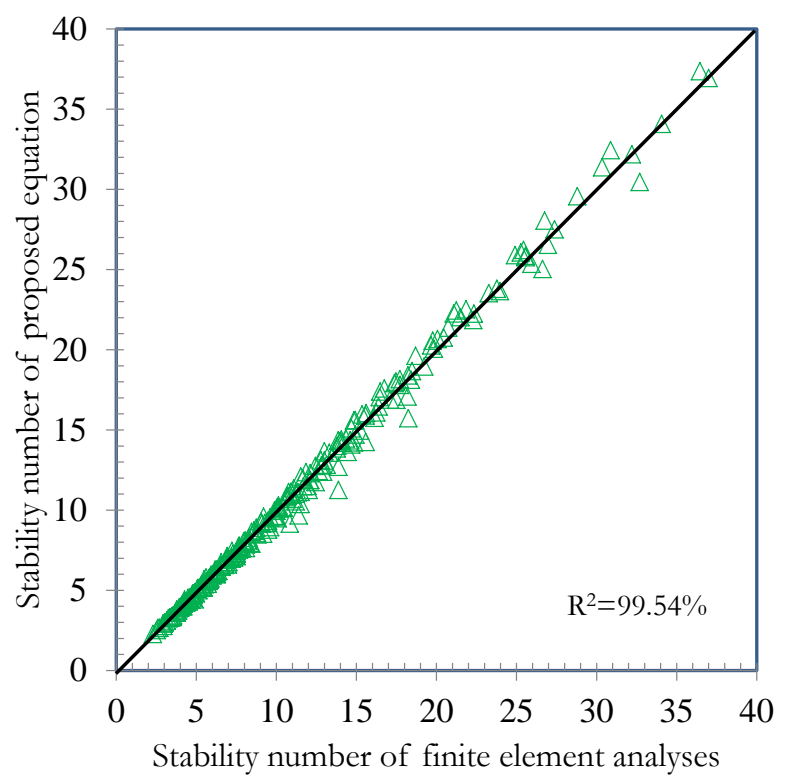

Fig. 20. Stability number of proposed equation versus that of finite element analysis based on 256 pieces of data from parametric studies.

\section{Application of Proposed Equation for Actual Case}

The proposed semi-analytical equation is applied to predict the stability of an excavation of a mine project (Mae Moh mine at "Area 4.1"), as described in the Introduction. According to the field data by [9], "Area 4.1" consists of two types of rock masses (shale and lignite) that rest on a bedding plane of clay seams which has low interface strength and a slope angle of $18^{\circ}$. Lignite and shale appear in the lower (toe) part and the upper (slope) part, respectively. The lignite mine in "Area 4.1 " is about $300 \mathrm{~m}$ in width, $33 \mathrm{~m}$ in thickness and $250 \mathrm{~m}$ in length along the pit wall. This area for lignite mining was planned by digging 3 benches with a height of $11 \mathrm{~m}$ each [33]. The slope might fail if the lignite at the toe part of slope were excavated or removed.

Based on [9] and [33], the properties of the clay seams and the shale were obtained by direct shear tests. The residual interface friction angle of the clay seams is $12^{\circ}$ with zero interface apparent adhesion. The internal friction angle and the cohesion of the shale at residual strength are $43^{\circ}$ and $71 \mathrm{kPa}$, respectively. The properties of the shale and the clay seams are summarized in Table 7.

The failure width of the excavation is obtained by solving the proposed empirical expression for the modified stability number in Eq. (10). According to the input parameters summarized in Table 7, the value of each normalized parameter can be calculated as follows: 


$$
\begin{aligned}
& x_{3}=\tan \left(45^{\circ}+43^{\circ} / 2\right)=2.29984 \\
& x_{4}=\frac{\cos \left(12^{\circ}\right)}{\sin \left(18^{\circ}-12^{\circ}\right)}=9.35772 \\
& z=\frac{\gamma T}{c}=8.88676
\end{aligned}
$$

Thus, substituting the calculated values for $x_{3}, x_{4}$ and $\mathrm{z}$ into the nonlinear Eq. (10), normalized parameter $x_{1}$ can be obtained as $x_{1}=0.221297$ and the failure width as $W=\frac{T}{x_{1}}=149 \mathrm{~m}$ under no seepage condition. Note that this value is closed to the maximum width of undercut slope in "Area 4.1" determined by Pipatpongsa et al. [33] under fully submerged condition using the designed unconfined compressive strength of shale $1 \mathrm{MPa}$.

In practice, a higher width should be used to ensure an adequate safety factor for the excavation. In order to minimize the total cost of a project, a lower factor of safety is usually employed in the design of mining projects [34]. In this study, a factor of safety of FS $=1.15$ is chosen to predict the required width of the excavation.

The conventional definition of factor of safety used in slope stability is applied in this calculation by determining the mobilized strength parameters of the apparent cohesion and the friction angle, as follows:

$$
\begin{gathered}
c=\frac{c_{\text {input }}}{F S} ; \tan \phi=\frac{\tan \phi_{\text {input }}}{F S} \\
c_{i}=\frac{c_{i, \text { input }}}{F S} ; \tan \phi_{i}=\frac{\tan \phi_{i, \text { input }}}{F S}
\end{gathered}
$$

where parameters with the subscript "input" are parameters obtained by the direct shear tests in Table 7 .

Thus, the mobilized soil parameters used in this case can be calculated as follows:

$$
\begin{gathered}
c=\frac{c_{\text {input }}}{F S}=61.74 ; \phi=\tan ^{-1}\left(\frac{\tan \phi_{\text {input }}}{F S}\right)=39.04^{\circ} \\
\phi_{i}=\tan ^{-1}\left(\frac{\tan \phi_{i, \text { input }}}{F S}\right)=10.47^{\circ}
\end{gathered}
$$

Next, similar calculations are conducted using those mobilized strength parameters, giving rise to each normalized parameter as:

$$
\begin{aligned}
& x_{3}=\tan \left(45^{\circ}+39.04^{\circ} / 2\right)=2.0983 \\
& x_{4}=\frac{\cos \left(10.47^{\circ}\right)}{\sin \left(18^{\circ}-10.47^{\circ}\right)}=7.5057 \\
& z=\frac{\gamma T}{c}=10.21977
\end{aligned}
$$

Thus, substituting the calculated values for $x_{3}, x_{4}$ and $z$ into the nonlinear Eq. (10), normalized parameter $x_{1}$ can be obtained as $x_{1}=0.32088$ and the required width as $W_{r q q}=\frac{T}{x_{1}}=102 \mathrm{~m}$.

Accordingly, it can be concluded that the failure width of the excavation using residual strength under no seepage condition is $149 \mathrm{~m}(\mathrm{FS}=1)$. In order to ensure an adequate safety factor of 1.15 , the required width of the excavation is $102 \mathrm{~m}$. 
Table 7. Input parameters for actual application.

\begin{tabular}{ccc}
\hline Parameters & Value & Unit \\
\hline Slope angle, $\alpha$ & 18 & degree \\
Internal friction angle, $\phi$ & 43 & degree \\
Cohesion, c & 71 & $\mathrm{kN} / \mathrm{m}^{2}$ \\
Interface friction angle, $\phi_{i}$ & 12 & degree \\
Thickness, $T$ & 33 & $\mathrm{~m}$ \\
Unit weight of soil, $\gamma$ & 19.12 & $\mathrm{kN} / \mathrm{m}^{3}$ \\
\hline
\end{tabular}

In practice, the case of slope with parallel seepage, where the water table above the failure plane and the direction of steady seepage are parallel to the slope, is commonly found in the field and more critical than that of a no seepage condition. A modification is necessary in order to apply the proposed empirical equation of a no seepage case to solve stability of a full seepage case, where the slope is fully submerged. This modification is achieved by examining an effect of seepage on a stability of an infinite slope. Based on conventional text books of soil mechanics (e.g., Das [35]), a factor of safety for an infinite slope resting on an interface friction plane with and without seepage are given as:

$$
\begin{gathered}
\text { No seepage, } F S=\frac{c_{i}}{\gamma_{m} H \cos ^{2} \alpha \tan \alpha}+\frac{\tan \phi_{i}}{\tan \alpha} \\
\text { Full seepage, } F S=\frac{c_{i}}{\gamma_{\text {sat }} H \cos ^{2} \alpha \tan \alpha}+\frac{\left(1-\frac{\gamma_{w}}{\gamma_{\text {sat }}}\right) \tan \phi_{i}}{\tan \alpha}
\end{gathered}
$$

where $H=$ vertical height of infinite slope; $T=$ thickness of infinite slope $=H \cos \alpha ; \gamma_{\mathrm{w}}=$ unit weight of water; $\gamma_{\mathrm{d}}=$ humid unit weight of soil; $\gamma_{\mathrm{sat}}=$ saturated unit weight of soil.

For the case of full seepage, it can be observed that the factor of safety of an infinite slope is affected by two parameters. First, a humid unit weight is replaced by a saturated unit weight for calculating a factor of safety. Second, a factor of $\left(1-\gamma_{\mathrm{w}} / \gamma_{\mathrm{sat}}\right)$ is applied to the tangent of interface friction angle, $\tan \phi_{i}$, which arises from an influence of water pressure at the inclined plane due to full seepage. As a result, the negative sign shows a reduction of total normal stress by the water pressure at the base, giving rise to the dimensionless reduced shear resistance of an interface friction plane, $\left(1-\gamma_{\mathrm{w}} / \gamma_{\mathrm{sat}}\right) \tan \phi_{\mathrm{i}}$ for the case of full seepage. Accordingly, proposed empirical expressions of stability number for a no seepage condition can be applied to the case of full seepage by employing the following empirical modifications.

1. A humid unit weight, $\gamma_{\mathrm{f}}$ in Eqs. (7) and (10) is replaced by a saturated unit weight, $\gamma_{\mathrm{sat}}$ for calculating a stability number, $\gamma_{\mathrm{f}} \mathrm{T} / \mathrm{c}_{\mathrm{i}}$.

2. A factor of $\left(1-\gamma_{\mathrm{w}} / \gamma_{\mathrm{sat}}\right)$ is applied to the tangent of interface friction angle, tan $\phi_{\mathrm{i}}$ by modifying the original term to a new term as follows:

$$
\begin{gathered}
\text { No seepage, } x_{4}=\frac{\cos \phi_{i}}{\sin \left(\alpha-\phi_{i}\right)}=\frac{1}{\sin \alpha-\tan \phi_{i} \cos \alpha} \\
\text { Full Seepage, } x_{4}=\frac{1}{\sin \alpha-\left(1-\gamma_{w} / \gamma_{\text {sat }}\right) \tan \phi_{i} \cos \alpha}
\end{gathered}
$$

The proposed modifications for a full seepage are applied to predict a failure width and required width of this problem with the same input conditions of a no seepage case as shown in Table 7 . For simplicity, it is assumed that a saturated unit weight is equal to a bulk unit weight. For the case of full seepage, the calculations with the new term $\mathrm{x}_{4}$ give rise to a failure width of $83 \mathrm{~m}(\mathrm{FS}=1)$ and a required width of $65 \mathrm{~m}$ with an adequate safety factor of 1.15. Such results are reasonable since both those widths of the seepage case are smaller than those of the no seepage case (i.e. $149 \mathrm{~m}$ for FS $=1 ; 102 \mathrm{~m}$ for FS $=1.15$ ) due to the influence of full seepage, which reduces effective normal stress acting on a relatively low interface friction plane. 


\section{Conclusions}

The 3D FEA has been employed to solve the stability of a soil block resting on a low interface friction plane with and without side supports. 3D FEA is required because the studied problem is classified as having three-dimensional geometry. The soil block and the interface plane are modeled as Mohr-Coulomb materials for both cases. The interfaces at the side supports are fully rough. The bottom interface plane is used to capture the shear sliding of the soil block on the low interface friction plane. The side interfaces help to increase the stability of the soil block with side supports.

For the case of the soil block on the low interface friction plane without side supports, there is a good agreement between the results of 3D FEA and LEM. Those results indicate that the stability number $\left(\gamma_{\mathrm{f}} \mathrm{T} / \mathrm{c}_{\mathrm{i}}\right)$ is independent of both the length and the width of the soil block, which corresponds to the measured data. For the thickness effect, the 3D FEA results match those of the physical model. The predicted results of 3D FEA illustrate that the soil block slides along the low interface friction plane, where no failure has occurred within the soil block. Furthermore, shear stresses on the interface plane are fully mobilized, where the relative shear stress ratio is unity.

For the case of the soil block on the low interface friction plane with side supports, the 3D FEA results reveal that the stability number $\left(\frac{\gamma_{f} T}{c_{i}}\right)$ is inversely proportional to the width of the soil block, where it does not depend on the length of the soil block. All the results of 3D FEA match those of the physical tests better than those of LEM. The limit equilibrium method, postulated from previous research, may not be accurate enough in the case of the soil block with side supports for steep slope angles. Predicted failure mechanisms show that the soil block slides on the low interface friction plane, where shear stresses on the bottom and the side interface planes are fully mobilized. Thus, failure happens at both the interface plane and the side interface planes.

An empirical equation is proposed for the soil block on the low interface friction plane with side supports based on the statistical approach of the curve fitting of 256 pieces of data from parametric studies. The correlation between the data of 3D FEA and the data of the proposed equation is very accurate, where the coefficient of determination, $\mathrm{R}^{2}$, is $99.54 \%$. This result indicates that the empirical equation can provide the best fit with the results of 3D FEA. The proposed equation is applied to predict the failure width and the required width of the excavation of an actual mining site as $149 \mathrm{~m}$ and $1^{\circ} 2 \mathrm{~m}$ using residual strength under no seepage condition for factors of safety of FS $=1$ and 1.15 , respectively. Simple modifications are proposed for applying the proposed empirical equation to a case of full seepage. Reasonable predictions of a full seepage case with the same input conditions as a no seepage case were obtained as: the failure width of $83 \mathrm{~m}(\mathrm{FS}=1)$ and the required width of $65 \mathrm{~m}(\mathrm{FS}=1.15)$.

\section{Acknowledgment}

This research was funded by the ASEAN University Network/ Southeast Asia Engineering Education Department Network (AUN/SEED-Net) Ph.D Sandwich Program under the Japanese International Cooperation Agency (JICA). The authors would like to express their gratitude to AUN/SEED-Net for financially supporting this research

\section{References}

[1] M. Budhu, Soil Mechanics and Foundations, 3rd ed. John Wiley \& Sons, 2011.

[2] D. J. Varnes, "Slope movement types and processes," Transportation Research Board Special Report. 1978.

[3] T. Pipatpongsa, M. Khosravi, C. Leelasukseree, N. Mavong, and J. Takemura, "Slope failures along oblique plane due to sequential removals of propping portion in physical model tests," presented at The 15th National Convention on Civil Engineering, Engineering Institute of Thailand, 2012.

[4] D. C. Drucker, W. Prager, and H. Greenberg, "Extended limit design theorems for continuous media," Quaterly of Applied Mechanics, vol. 9, pp. 381-388, 1952.

[5] J. M. Duncan, "State of the art: limit equilibrium and finite-element analysis of slopes," Journal of Geotechnical engineering, vol. 122, no. 7, pp. 577-596, 1996. 
[6] W. Wei and Y. Cheng, "Strength reduction analysis for slope reinforced with one row of piles," Computers and Geotechnics, vol. 36, no. 7, pp. 1176-1185, 2009.

[7] Z. Weifeng, Z. Lianheng, and D. Dongping, "Improved sliding surface search method for stability analysis of complex slopes," Procedia Earth and Planetary Science, vol. 5, pp. 88-93, 2012.

[8] H. Yu, R. Salgado, S. Sloan, and J. Kim, "Limit analysis versus limit equilibrium for slope stability," Journal of Geotechnical and Geoenvironmental Engineering, vol. 124, no. 1, pp. 1-11, 1998.

[9] M. H. Khosravi, "Arching effect in geomaterials with applications to retaining walls and undercut slopes," Ph.D. dissertation, Tokyo Institute of Technology, 2012.

[10] A. W. Jenike, "Steady gravity flow of frictional-cohesive solides in converging channels," Journal of Applied Mechanics, vol. 31, no. 1, pp. 5-11, 1964.

[11] Z. Chen, J. Wang, Y. Wang, J.-H. Yin, and C. Haberfield, "A three-dimensional slope stability analysis method using the upper bound theorem Part II: numerical approaches, applications and extensions," International Journal of Rock. Mechanics and Mining Sciences., 38(3), pp. 379-397, 2001.

[12] Z. Chen, X. Wang, C. Haberfield, J.-H. Yin, and Y. Wang, "A three-dimensional slope stability analysis method using the upper bound theorem: Part I: theory and methods," International Journal of Rock Mechanics and Mining Sciences, vol. 38, no. 3, pp. 369-378, 2001.

[13] S. Sloan, "Geotechnical stability analysis," Géotechnique, vol. 63, no. 7, pp. 531-571, 2013.

[14] D. C. Drucker, H. Greenberg, and W. Prager, The Safety Factor of an Elastic-Plastic Body in Plane Strain. Brown University: Division of Applied Mathematics, 1951.

[15] W. Alkasawneh, A. I. H. Malkawi, J. H. Nusairat, and N. Albataineh, "A comparative study of various commercially available programs in slope stability analysis, Computers and Geotechnics, vol. 35, no. 3, pp. 428-435, 2008.

[16] E. Dawson, W. Roth, and A. Drescher, "Slope stability analysis by strength reduction," Geotechnique, vol. 49, no. 6, pp. 835-840, 1999.

[17] D. Griffiths and P. Lane, "Slope stability analysis by finite elements," Geotechnique, vol. 49, no. 3, pp. 387-403, 1999.

[18] S. Mohammadi and H. A. Taiebat, "A large deformation analysis for the assessment of failure induced deformations of slopes in strain softening materials," Computers and Geotechnics, vol. 49, pp. 279-288, 2013.

[19] H. Zheng, G. Sun, and D. Liu, "A practical procedure for searching critical slip surfaces of slopes based on the strength reduction technique, Computers and Geotechnics, vol. 36, no. 1, pp. 1-5, 2009.

[20] M. Khosravi, L. Tang, T. Pipatpongsa, J. Takemura, and P. Doncommul, "Performance of counterweight balance on stability of undercut slope evaluated by physical modelling," International Journal of Geotechnical Engineering, vol. 6, no. 2, pp. 193-205, 2012.

[21] M. H. Khosravi, T. Pipatpongsa, A. Takahashi, and J. Takemura, "Arch action over an excavated pit on a stable scarp investigated by physical model tests," Soils and Foundations, vol. 51, no. 4, pp. 723-735, 2011.

[22] T. Techawongsakorn, H. Hirai, M. Khosravi, and T. Pipatpongsa, "Slip mechanisms and interface shear strength between moist silica sand and acrylic plate," in Proceedings of the 48th Japan National Conference on Geotechnical Engineering, 2013.

[23] R. Brinkgreve, Plaxis 3D 2012. Netherland: Plaxis Bv, 2012.

[24] E. Davis, "Theories of plasticity and the failure of soil masses," in Soil Mechanics: Selected Topics, 1968, pp. 341-380.

[25] A.-J. Li, R. Merifield, and A. Lyamin, "Limit analysis solutions for three dimensional undrained slopes," Computers and Geotechnics, vol. 36, no. 8, pp. 1330-1351, 2009.

[26] A.-J. Li, R. S. Merifield, and A. V. Lyamin, "Three-dimensional stability charts for slopes based on limit analysis methods," Canadian Geotechnical Journal, vol. 47, no. 12, pp. 1316-1334, 2010.

[27] R. Brinkgreve, E. Engin, and W. Swolfs, Plaxis 3D 2012 Manual. The Netherlands: Plaxis bv, 2012.

[28] A. Jenike, "Steady gravity flow of frictional-cohesive solids in converging channels," Journal of Applied Mechanics, vol. 31, no. 1, pp. 5-11, 1964.

[29] R. Butterfield, "Dimensional analysis for geotechnical engineers," Geotechnique, vol. 49, no. 3, pp. 357366, 1999.

[30] A. A. Sonin, The Physical Basis of Dimensional Analysis. Cambridge, MA: Department of Mechanical Engineering, MIT, 2001.

[31] D. V. Griffiths and G. A. Fenton, Probabilistic Methods in Geotechnical Engineering. Springer Science \& Business Media, 2007. 
[32] D. C. Montgomery and G. C. Runger, Applied Statistics and Probability for Engineers. John Wiley \& Sons, 2009.

[33] T. Pipatpongsa, M. Khosravi, and J. Takemura, "Physical modeling of arch action in undercut slopes with actual engineering practice to Mae Moh open-pit mine of Thailand," in Proceedings of the 18th International Conference on Soil Mechanics and Geotechnical Engineering (ICSMGE18), Paris, 2013, pp. 943 946.

[34] J. Botin, Sustainable Management of Mining Operations. SME, 2009.

[35] B. M. Das, Principles of Foundation Engineering, 8th ed. Cengage Learning, 2014. 